\title{
Coronin 1A facilitates calcium mobilization and promotes astrocyte reactivity in HIV-1 Neuropathogenesis
}

Hriday Shanker Pandey

National Brain Research Centre

Rishabh Kapoor

National Brain Research Centre

Bindu

National Brain Research Centre

Pankaj Seth ( $\square$ pseth.nbrc@gov.in )

National Brain Research Centre https://orcid.org/0000-0003-1021-7839

\section{Research Article}

Keywords: astrocytes, calcium mobilization, Coronin 1A, reactive astrocytes, neuroinflammation, GFAP, neuroAIDS, glia-mediated neurodegeneration, HIV-1 neuropathogenesis

Posted Date: March 22nd, 2021

DOI: https://doi.org/10.21203/rs.3.rs-104465/v3

License: (c) (i) This work is licensed under a Creative Commons Attribution 4.0 International License. Read Full License

Version of Record: A version of this preprint was published at FASEB BioAdvances on November 10th, 2021. See the published version at https://doi.org/10.1096/fba.2021-00109. 


\section{Abstract}

\section{Background}

In most neurodegenerative disorders, including neuroAIDS, reactive astrocytes are detrimental to the neuronal population. Calcium and its downstream regulators play a central role in mediating astrocyte reactivity. Coronin $1 \mathrm{~A}$, an actin binding protein, majorly reported in hematopoietic cells, regulates cell activity in a calcium-dependent manner, but its role in astrocyte physiology and reactivity is largely unknown. We explored the roles of Coronin $1 \mathrm{~A}$ in astrocyte physiology and its involvement in facilitating astrocyte reactivity.

Methods

Coronin 1A expression was assessed in astrocytes and human brain autopsy sections using western blotting, immunocytochemistry, and immunohistochemistry. siRNA-mediated downregulation was performed to assess its loss of function. To assess the cell activity, live-cell calcium imaging was performed on ATP-stimulated astrocytes using a confocal microscope. HIV-1 Tat B expression vector was used to induce astrocyte reactivity, after which gene and protein expressions were assessed using qPCR and western blotting; cytokine release was measured using flow cytometry and glutamate release was assessed using enzymatic activity. TUNEL assay was performed on neurons treated with the astrocyteconditioned media. Small RNA-sequencing and qPCR assays were performed to list miRNAs differentially regulated as a result of HIV-1 Tat transfection. Transfection with mimic and inhibitor against selected miRNA and luciferase assay was performed to confirm the miRNA regulation.

Results

We report Coronin $1 \mathrm{~A}$ expression in human primary astrocytes and autopsy brain sections, and that it plays activity-dependent roles by facilitating Calcium mobilization from the intracellular stores. HIV-1 Tat, a potent neurotoxicant that turns astrocytes reactive, augments Coronin $1 \mathrm{~A}$ expression, apart from affecting GFAP and pro-inflammatory molecules. Also, the autopsy brain tissue of HIV-1 infected individuals has higher Coronin 1A expression. Downregulation of Coronin 1A attenuated the HIV-1 Tatinduced deleterious effects of reactive astrocytes, measured as upregulated GFAP expression, enhanced release of IL-6, and Glutamate and hence reduced astrocyte-mediated neuroinflammation. Our findings also suggest that out of a pool of dysregulated miRNAs studied by us, hsa-miR-92b-5p regulates Coronin $1 \mathrm{~A}$ expression under the effect of HIV-1 Tat.

Conclusion

These findings highlight the novel roles of Coronin $1 \mathrm{~A}$ in regulating astrocyte activity in stimulated conditions and astrocyte reactivity observed in HIV-1 neuropathogenesis.

\section{Background}


Extensive studies on glial cells conducted over the past 30 years, strongly advocate that astrocytes are more than mere supporting cells as they perform many essential functions ranging from neurodevelopment to synaptic plasticity \{reviewed in $(1,2)\}$. Also, growing evidence point towards the fact that astrocytes undergo morphological (including hypertrophy) and molecular changes in various inflammatory or pathological conditions. These changes can further affect the neuronal population. Astrocyte reactivity encompasses all such changes including the increase in protein expression of intermediate filaments such as glial fibrillary acidic protein (GFAP) and vimentin followed by the enhanced release of numerous factors, can be beneficial or detrimental for the neurons, based on the context or the neuropathology, is also regulated by a number of factors $(3,4)$. Many of the released factors can also serve as the mediators of the innate immune system (5).

Astrocytes play a significant role in human immunodeficiency virus (HIV)-1 neuropathogenesis (6-8). In fact, in the post-HAART era, the glia-mediated indirect neuronal death is prominent over the direct death of the neurons caused by the virus or the viral proteins. Astrocytes contribute significantly to the indirect neuronal death and thus amplify the toxic effects brought about by the activated and/or infected microglia. Up to $19 \%$ of astrocytes are found to be positive for HIV-1 DNA in subjects with HIV-associated dementia (9). The extent of HIV-1 infection in astrocytes is correlated with the severity of the neurological problems associated with AIDS patients. HIV-1 infection in astrocytes is non-productive due to the reduced translation of Gag, Env, and Nef mRNAs, whereas the translation of, transactivator of transcription (Tat) mRNA remains unaltered. Studies in the mice model show that HIV-1 Tat is sufficient to induce progressive cognitive abnormalities such as impaired learning and memory deficits (10-12). Astrocyte reactivity, induced either by HIV-1 infection, the viral proteins, or factors released by other infected cell types, is a key factor in mediating neuronal loss by various mechanisms. Hence, there is an urgent need to better understand the mechanisms which make this supporting cell type reactive and detrimental in the context of neuroAIDS.

Calcium is an important regulator of astrocyte activity. Calcium signaling in astrocytes once doubted to be significant to bring forth changes in neuronal functions, is now well known to be significantly affecting neuronal physiology (13). Astroglial $\left[\mathrm{Ca}^{2+}\right]_{i}$ flux triggered by neurotransmitters leads to the release of gliotransmitters such as glutamate (14), D-serine (15), and adenosine triphosphate (ATP) (16), which after binding to their receptors can cause neuronal excitation (17). HIV-1 Tat induces $\mathrm{Ca}^{2+}$ mobilization in astrocytes from the extracellular milieu or the intracellular stores. These events dysregulate the $\left[\mathrm{Ca}^{2+}\right]_{\mathrm{i}}$ and facilitate altered cell physiology and neuronal death (18).

We investigated the role of coronin $1 \mathrm{~A}$ in modulating calcium signaling and astrocyte reactivity in the context of neuroAIDS. Coronin 1A belongs to the coronin family of proteins. The presence of WD repeats in the N-terminal is the hallmark of this family. Coronin $1 \mathrm{~A}$ is encoded on chromosome 7 in mice and 16 in humans. This $57 \mathrm{kDa}$ protein is expressed majorly by cells of hematopoietic origin and also in nervous tissue (19-22). By mediating outside to inside signal transduction, it regulates a number of processes such as phagocytosis in various cell types, and activation of T cells (23-25). The expression and 
functions of coronin 1A in different brain cell types are still underexplored and await detailed molecular investigations.

In this study, we delineated the activity-dependent roles of coronin 1A in cells of non-hematopoietic origin and its involvement in mediating astrocyte reactivity in the presence of neuroinflammatory agent such as HIV-1 Tat. Our experiments were focused to investigate the mechanisms of coronin $1 \mathrm{~A}$ regulations and how it contributes to the indirect neuroinflammation observed in HIV-1 neuropathogenesis.

\section{Methods}

\section{Human Fetal Brain-Derived Neuronal Precursor Cell Culture}

Human brain tissues collected from elective abortions with the informed consent of mothers, were processed as per the protocols laid down by the Institutional Human Ethics and Stem Cell Research Committee under strict compliance with the guidelines of ICMR, India. Neural Precursor Cells (NPCs) were derived from the telencephalon region of the aborted fetuses of age 10-14 weeks. NPCs were cultured on poly-D-lysine (Sigma-Aldrich, Missouri, USA) coated flasks in Neurobasal Media (Invitrogen, California, USA) supplemented with N2 supplement (Invitrogen, USA), Neural Survival Factor-1 (Lonza, Charles City, IA), $20 \mathrm{ng} / \mathrm{mL}$ EGF (Sigma-Aldrich, USA) and $25 \mathrm{ng} / \mathrm{mL}$ bFGF (Sigma-Aldrich, USA). NPCs were further assessed for the expression of markers such as Nestin and SOX2 and $99 \%$ of the cells were found to be positive. They were also assessed for their ability to form neurospheres and differentiate into Astrocytes and Neurons.

\section{Human Primary Astrocytes and Neuronal Culture}

NPCs were differentiated into astrocytes by replacing the media with Eagle's Minimal Essential Media (MEM) (Sigma-Aldrich, USA) containing 10\% Fetal Bovine Serum (Gibco, California, USA). These cells were cultured for 3 weeks, with half media changes on alternate days, after which they were assessed for the expression of GFAP and Vimentin, for which more than $95 \%$ of cells were found immunopositive (Supplementary Figure S1, Additional File 1). To differentiate NPCs into neurons, EGF and FGF from NPC media were replaced with $10 \mathrm{ng} / \mathrm{mL}$ BDNF (Peptrotech, New Jersey, USA) and $10 \mathrm{ng} / \mathrm{mL}$ PDGF-AB (Peptrotech, New Jersey, USA). After maintaining them for 3 weeks, with half media changes on alternate days, they were assessed for expression of Tuj-1 and MAP2, for which more than $95 \%$ of cells were immunopositive.

\section{$\left[\mathrm{Ca}^{2+}\right]_{\mathrm{i}}$ measurement / Live cell imaging}

0.2 million cells were seeded in 35-mm dishes and incubated with $2.5 \mathrm{mM}$ Fluo-4-AM (Invitrogen, USA) in HEPES buffer at $37^{\circ} \mathrm{C}$ for $30 \mathrm{~min}$. After 3 washes, the dish was mounted on the stage for live-cell imaging using a spinning disc confocal microscope (Zeiss, Oberkochen, Germany) 10 x objective (Zeiss, Germany) was used for the measurement of fluorescent intensity as a measure of the change in $\left[\mathrm{Ca}^{2+}\right]_{\mathrm{i}}$. Baseline fluorescence intensity was recorded for the initial 1 minute, thereafter, 10 mM ATP (Sigma- 
Aldrich, USA) was added to the static bath followed by 5 min of recording. Change in fluorescence intensity was calculated by subtracting fluorescence at $t=0$ from all the fluorescence intensity values. ZEN software (Zeiss, Germany) was used for data acquisition and analysis. Areas having a significant number of cells $(\geq 50)$ were randomly selected for the recordings after which individual cells were marked as the region of interest and fluorescence intensity was measured across time.

\section{Immunocytochemistry}

Astrocytes were seeded in a 4-well chamber slide (Nunc, Kamstrupvej, Denmark) at a density of 30,000 cells per well. After $24 \mathrm{~h}$, the cells were fixed using $4 \%$ paraformaldehyde, washed thrice with 1X PBS, blocked, and permeabilized using 4\% BSA containing $0.4 \%$ Triton-X 100 . The cells were then incubated with antibodies, mouse anti-Coronin 1A (Santa Cruz Biotechnology, Texas, USA, 1:100), moues anti- Ki 67 (Millipore, Billerica, USA, 1:1000), mouse anti-Vimentin (Santa Cruz Biotechnology, USA, 1:1000),

overnight at $4{ }^{\circ} \mathrm{C}$ or Anti-GFAP (Dako, California, USA, $1: 1000$ ) for $1 \mathrm{~h}$ at $25^{\circ} \mathrm{C}$. The cells were then washed thrice with $1 \mathrm{X}$ PBS and incubated with appropriate fluorophore-tagged secondary antibodies (Invitrogen, USA, 1:1000). The wells were washed thrice with $1 X$ PBS and mounted using Hardset mounting media with DAPI (Vector Labs, Burlingam, USA). For each group, a minimum of five images were captured from random fields using the Axiolmager Z1 microscope (Zeiss, Germany).

\section{Immunohistochemistry}

Formalin-Fixed Paraffin-Embedded (FFPE) patient brain tissue sections were first deparaffinized and rehydrated. Sections were quenched with $1 \% \mathrm{H}_{2} \mathrm{O}_{2}$ followed by antigen retrieval. Permeabilization was done using $0.1 \%$ Triton-X in 1 X PBS and later-on blocked with $1 \%$ BSA, 3\% Goat or Rabbit Serum, $0.05 \%$ Triton-X in $1 X$ PBS. Sections were incubated overnight with primary antibodies, goat anti-Coronin $1 \mathrm{~A}$ (Abcam, Cambridge, UK, 1:25), rabbit anti-GFAP (Dako, USA, 1:500) in blocking solution. Sections were washed 4 times with $0.02 \%$ Tween 20 in 1 X PBS (PBST). Secondary antibody incubation was done for 2 hours with appropriate biotinylated antibody (Vector labs, USA, 1:500). Washing was done 4 times using PBST and sections were then treated with a complex of Avidin-Biotinylated HRP (Vector Labs, USA, 1:1) for 2 hours followed by 4 PBST washes. Sections were developed for 1-3 minutes using ImmPACT NovaRED kit (Vector Labs, USA) following the manufacturer's protocol, counterstained with Hematoxylin, and washed under running water. The sections were dried, treated with xylene, and then mounted using DPX mountant solution. Each section was imaged thrice randomly using Leica DMRXA2 (Leica, Wetzlar, Germany) microscope at 10x, 20x, and 40x magnifications. Images were then processed and analyzed using ImageJ software (NIH, USA).

\section{ATP Stimulations}

Astrocytes knocked down for coronin $1 \mathrm{~A}$ for $48 \mathrm{~h}$ were serum-starved for 2-3 $\mathrm{h}$ and then stimulated with $10 \mathrm{mM}$ ATP (Sigma-Aldrich, USA). ATP stimulations were given for either $0,45,120$, and $300 \mathrm{sec}$ or 5, 10, $30,60,120$ min, after which the cells were harvested using lysis buffer. The lysates were further processed for protein analysis. 
Astrocyte cultures with $80 \%$ confluency were used for transfections with expression vector pcDNA3.1 expressing full-length HIV-1 Tat B, which was a kind gift from Prof. Udaykumar Ranga, Jawaharlal Nehru Centre for Advanced Scientific Research (JNCASR), India. Transfections were done using Lipofectamine 3000 (Invitrogen, USA) as per the manufacturer's protocol. After $24 \mathrm{~h}$ of transfection, cells were further harvested as per the experimental requisite.

\section{Small Interfering RNA (siRNA) mediated knockdown of coronin 1A}

Human primary astrocytes were knocked down using siRNA against coronin 1A. $10 \mathrm{nM}$ coronin 1A siRNA (Dharmacon, Colorado, USA) or control scrambled siRNA (Dharmacon, USA) was transfected twice, using lipofectamine RNAimax (Invitrogen, USA) following manufacturer's protocol. The cells were either harvested after $48 \mathrm{~h}$ of transfection to check the knockdown efficiency or carried over for further treatments or transfections.

\section{Western Blotting}

The cells were harvested using lysis buffer, which consisted of $50 \mathrm{mM}$ Tris- $\mathrm{HCl}(\mathrm{pH} 7.5), 150 \mathrm{mM} \mathrm{NaCl}, 50$ $\mathrm{mM}$ Sodium fluoride, $1 \mathrm{mM}$ sodium orthovanadate, $1 \mathrm{mM}$ EDTA ( $\mathrm{pH}$ 8.0), 2\% SDS, and protease inhibitor cocktail (Roche, Basel, Switzerland). Estimation of protein concentration was done using 4\% copper sulfate and bicinchoninic acid (Sigma-Aldrich, USA). Proteins were resolved on 10-13\% SDS- PAGE and transferred onto a nitrocellulose membrane (MDI, Ambala, India). The blots were blocked using 5\% skimmed milk in PBS-Tween 20 (PBST) followed by incubation with primary antibodies, mouse antiCoronin 1A (Santacruz biotech, USA, 1:500), mouse anti-GAPDH (Santacruz biotech, USA, 1:1000), rabbit anti-Phospho-p44/42 MAPK (Cell Signaling Technology, Massachusetts, USA, 1:2000), rabbit anti-p44/42 MAPK (Cell Signaling Technology, USA, 1:2000), rabbit anti-Phospho-PLCY1 (Cell signaling, USA,1:1000), rabbit anti-PLCY1 (Cell signaling, USA,1:1000), rabbit anti-GFAP (Dako, USA, 1:20000). Blots were washed thrice with TBS-Tween 20 (TBST) and then incubated with appropriate HRP labeled secondary antibodies (Vector Labs, USA, 1:4000) for $2 \mathrm{~h}$ at room temperature. The blots were washed thrice with TBST and then developed using Chemiluminescent Reagent (Millipore, USA) and were imaged using Gel Documentation System (Uvitech, Cambridge, UK). Densitometry of the protein bands was done using ImageJ software (NIH, Maryland, USA).

\section{Quantitative Real-Time PCR}

The cells were harvested for RNA isolation using Trizol reagent (Ambion, Texas, USA) following the manufacturer's protocol. The purified RNA was utilized for synthesizing CDNA using High-capacity cDNA Reverse Transcriptase Kit (Applied Biosystems, California, USA). qPCR was performed using SYBR Green Master Mix (Applied Biosystems, USA) using the following primers: CORO1A forward 5'-

CACCAACATCGTCTACCTCTG-3' and reverse 5'-ACTCCTTGGAACTGAACATGG-3', GAPDH forward 5'CAAGAGCACAAGAGGAAGAGAG-3' and reverse 5'-CTACATGGCAACTGTGAGGAG-3', GFAP forward 5'- 
ACCTGCAGATTCGAGAAACCAG-3' and reverse 5'-TAATGACCTCTCCATCCCGCATC-3', Vimentin forward 5'AAGTCCGCACATTCGAGCAA-3' and reverse 5'-CTACCAACTTACAGCTGGGC-3', VCAM1 forward 5'GGGAAGCCGATCACAGTCAA-3' and reverse 5'-TCCTGTCTGCATCCTCCAGA-3', ICAM1 forward 5'CCGCAGTCATAATGGGCACT-3' and reverse 5'-GGTTTCATGGGGGTCCCTTT-3', PTGS2 forward 5'TGTATGAGTGTGGGATTTGACC-3' and reverse 5'-TGTGTTTGGAGTGGGTTTCAG-3', NOS2 forward 5'CTTTGCCTGTATGCTGATGC-3' and reverse 5'-GCCTCTGATTTTCCTGTCTCTG-3'.

miRNA along with total RNA was isolated using the miRNEASY mini kit (Qiagen, Hilden, Germany) following the manufacturer's protocol. Subsequently, the cDNA was synthesized using the miScript II RT kit (Qiagen, Germany) as per the manufacturer's protocol. The qPCR assay was done using the miScript SYBR Green PCR kit (Qiagen, Germany) following the manufacturer's protocol. The qPCR was done in ViiA7 ${ }^{\mathrm{TM}}$ (Applied Biosystems, USA). The specificity of the primers was confirmed via analyzing the melt curve.

\section{IL-6-release measurement by Flow-cytometry}

Astrocyte-conditioned-media (ACM) was collected from astrocytes knocked down for coronin $1 \mathrm{~A}$ for $48 \mathrm{~h}$ and transfected with HIV-1 Tat for $24 \mathrm{~h}$. The conditioned-media thus collected was then analyzed for the levels of released pro-inflammatory cytokine interleukin-6 (IL-6) by using flow-cytometry-based Cytometric bead array (CBA)-human inflammatory cytokines kit (BD Biosciences, San Diego, USA), and following manufacturer's protocol.

\section{Glutamate-release measurement}

ACM was collected from astrocytes knocked down for coronin $1 \mathrm{~A}$ for $48 \mathrm{~h}$ and transfected with HIV-1 Tat for $24 \mathrm{~h}$. The conditioned media thus collected was analyzed for the levels of released glutamate using an enzyme kinetics-based glutamate determination kit (Sigma-Aldrich, USA), following the manufacturer's protocol.

\section{Assessment of Neuronal Survival by TUNEL Assay}

ACM was collected from astrocytes knocked down for coronin $1 \mathrm{~A}$ for $48 \mathrm{~h}$ and transfected with HIV-1 Tat for $24 \mathrm{~h}$. Neurons at a density of 20,000 cells/well were seeded in Poly-D-Lysine coated 8 well-chambered slides. The next day the cells were treated with 50\% ACM and Neuronal Media for $24 \mathrm{~h}$. Cells were then fixed using $4 \%$ paraformaldehyde. Washed thrice with $1 \times$ PBS, blocked and permeabilized using $4 \%$ BSA containing $0.1 \%$ Triton-x 100 . Cells undergoing apoptosis were detected using in situ Cell Death Detection Kit, TMR red (Roche, Switzerland), following the manufacturer's protocol. Cells were washed thrice with $1 \mathrm{x}$ PBS, and the slide was mounted using Hardset mounting media with DAPI (Vector Labs, USA). Five images were captured for each group using the Axiolmager Z1 microscope (Zeiss, Germany).

\section{miRNA Target Prediction}


miRWalk (http://mirwalk.umm.uni-heidelberg.de/) online prediction tool was used to filter miRNAs targeting 3' UTR of CORO1A.

\section{miRNA Mimic and Inhibitor Transfection}

Transfection was done on astrocytes, in $80 \%$ confluent T25 flasks using RNAi MAX (Invitrogen, USA) as per the manufacturer's protocol. $62.5 \mathrm{nM}$ of Syn-hsa-miR-92b-5p miScript miRNA mimic (Qiagen, Germany) was used for mimic transfection. All-Stars Negative Control siRNA (Qiagen, Germany) was used as mimic control. miRNA inhibition was done using $62.5 \mathrm{nM}$ of miRCURY LNA miRNA inhibitor against has-miR-92b-5p (Qiagen, Germany) and miRCURY LNA miRNA Inhibitor Control (Qiagen, Germany) was used as the inhibitor control. Transfections were done using Opti-MEM media (Invitrogen, USA) for $5 \mathrm{~h}$ and replaced with complete MEM. Cells were processed after 48 hours of transfection for RNA and Protein analysis. Effective doses of mimic and inhibitor miRNA were standardized via qPCR and protein studies.

\section{Cloning of CORO1A 3' UTR and Luciferase Assay}

The 3' UTR sequence of coronin 1A, being very short in length (111 bp), was outsourced in the form of 2 single-stranded nucleotide chains having restriction sites for Spel and HindllI respectively. Both the chains were annealed, digested, and was cloned into pMIR-Report plasmid between Spel and Hindlll restriction sites. The cloned plasmid was then sequenced to confirm the successful insertion.

COR01A 3'UTR luciferase reporter plasmid was co-transfected with $12.5 \mathrm{nM}$ of mimic-92b-5p into HeLa cells, using Lipofectamine 3000 as per manufacturer's protocol. After $24 \mathrm{~h}$ the samples were harvested for luciferase detection, using Luciferase Detection Kit (Promega, Wisconsin, USA) following the manufacturer's protocol, in Tecan SPARK multiplate reader (Tecan, USA). The readings were normalized using total protein content.

\section{Statistical Analysis}

Experiments of all kinds were performed independently three to five times; Student's t-test was used to assess statistical significance between control and experimental groups. $P$ values $<0.05$ were considered statistically significant. * represents $p<0.05,{ }^{*} p<0.005$, and ${ }^{* \star *} p<0.0005$.

\section{Results}

\section{Coronin 1A expression in human brain cells and brain autopsy tissue}

Coronin 1A expression has been reported majorly in cells of hematopoietic origin $(20,23,26)$ and neurons (22) but its expression in astrocytes was not explored till this study. In this regard, human brain cells were harvested to assess the protein levels of coronin $1 \mathrm{~A}$ through western blotting. Jurkat $\mathrm{T}$ cells were taken as a positive control for coronin $1 \mathrm{~A}$ expression. We found coronin $1 \mathrm{~A}$ expression in all the brain cell types viz NPCs, astrocytes, and neurons (Fig. 1a). The levels of the GAPDH protein varied in different lanes, this 
might be because of its differential expression across cell types assessed. Additionally, immunocytochemistry was performed which confirmed coronin $1 \mathrm{~A}$ (green) localization in the cells along with a marker for astrocytes, GFAP (red) (Fig. 1b). Coronin 1A was also found to be expressed in the human brain autopsy sections. Immunohistochemistry performed on the hippocampal sections revealed Coronin 1A expression, as compared to the negative control (NC) (Fig. 1c).

\section{Coronin $1 \mathrm{~A}$ is dispensable in resting-state human astrocytes}

The functional roles of coronin $1 \mathrm{~A}$ in astrocytes were unexplored, therefore, to study the role of coronin $1 \mathrm{~A}$ in astrocytes, we carried out a loss of function experiments on human astrocytes. We performed siRNAmediated knockdown and checked the knockdown efficiency after $48 \mathrm{~h}$; the siRNA was found to reduce the mRNA levels by $83 \% \pm 4 \%(p<0.0005)$ and protein levels by $41 \% \pm 2 \%(p<0.0005)$ (Fig. $2 a$ and $2 b$, respectively). To check if the coronin $1 \mathrm{~A}$ knockdown results in cell death, we performed a live-dead cell assay on coronin 1A siRNA transfected astrocytes. We found that there was no significant difference in the live-dead cell proportions in the siRNA transfected group compared to the control scrambled siRNA transfected group (Supplementary Figure S2a, Additional File 1). Mature astrocytes are low-proliferating cells though, but whatever the rate of proliferation be, was found to be unaffected by coronin $1 \mathrm{~A}$ knockdown, as assessed through immunocytochemistry using Ki-67 protein as a marker for proliferation (Supplementary Figure S2b, Additional File 1). Further, to assess the role of coronin 1A in resting-state cell physiology, if any, we checked the expression of intermediate filament proteins such as GFAP and Vimentin. It was found that downregulating coronin 1A neither affected GFAP protein (although mRNA slightly affected) (Fig. 2c, d) nor vimentin protein expression (Fig. 2e, f). These results signify that coronin $1 \mathrm{~A}$ is dispensable in resting-state astrocytes and hence prompted us to explore if its functions are activity-dependent.

\section{Coronin 1A facilitates Calcium mobilization and $\mathrm{Ca}^{2+}$ dependent pathways in stimulated human astrocytes}

$\mathrm{Ca}^{2+}$ mobilization upon stimulation with a ligand is a good measure of astrocyte activity and can be correlated with the effects of astrocyte activity on neuronal population $(13,27)$. ATP is a well-known and widely used gliotransmitter that can induce calcium mobilization $(28,29)$. To investigate the role of coronin $1 \mathrm{~A}$ in stimulated astrocytes, fluorescence-based live-cell calcium imaging was performed upon stimulation with ATP. An increase in the fluorescence of the calcium-sensitive dye Fluo-4 was taken as a measure of $\mathrm{Ca}^{2+}$ flux. An increase in intracellular calcium upon ATP stimulation was recorded in HEPES buffer $\left(+/-\mathrm{CaCl}_{2}\right)$. Basal fluorescence was recorded for $1 \mathrm{~min}$ and then $10 \mu \mathrm{M}$ ATP was applied to the bath and recordings were performed for an additional $5 \mathrm{~min}$. ATP stimulation induced the $\mathrm{Ca}^{2+}$ flux and fluorescence intensity increased. In the absence of $\mathrm{CaCl}_{2}$ in the HEPES buffer (i.e., source of $\mathrm{Ca}^{2+}$ is just intracellular), astrocytes downregulated for coronin 1A showed a 2.67-fold decrease in fluo-4 fluorescence as compared to the control group $(p<0.05)$, suggestive of its role in calcium mobilization in stimulated conditions (Fig. 3a). The $\mathrm{Ca}^{2+}$ flux compromise observed when the HEPES buffer with $\mathrm{CaCl}_{2}$ was used 
(i.e., source of $\mathrm{Ca}^{2+}$ is both, intra- and extracellular), was not statistically significant (Fig. 3b). This indicated that coronin $1 \mathrm{~A}$ downregulation affected the calcium mobilization from the intracellular stores.

The reduced $\mathrm{Ca}^{2+}$ flux in coronin $1 \mathrm{~A}$ knocked-down cells could be an outcome of the altered PLCY1 phosphorylation. To assess this possibility, astrocytes transfected with control scrambled siRNA or coronin $1 \mathrm{~A}$ targeting siRNA were stimulated with $10 \mu \mathrm{M}$ ATP for varying time points $(0,45,120$, and 300 sec) after which the cells were harvested and the whole cell lysate was analyzed through western blotting for the phosphorylated and the total forms of PLCY1. It was observed that coronin 1A knockdown resulted in reduced PLCY1 phosphorylation as compared to the control group (at $t=120 \mathrm{sec} ; \mathrm{p}<0.05$ ) (Supplementary Figure S3a, Additional File 1). We also assessed the ERK1/2 phosphorylation pattern after ATP stimulations for varying time-points $(0,5,10,30,60$, and $120 \mathrm{~min})$ and observed a slight decrease in ERK1/2 phosphorylation, although not significant (Supplementary Figure S3b, Additional File 1). The above results indicate that, although coronin $1 \mathrm{~A}$ is dispensable in the resting-state but plays activity-dependent roles by facilitating calcium mobilization from the intracellular stores upon stimulation.

\section{Coronin 1A is upregulated in HIV-1 Tat-induced reactive astrocytes and brain autopsy sections of HIV-1 infected individuals}

Neuroinflammatory agent HIV-1 Tat is a well-known neurotoxicant that induces astrocyte reactivity and hence causes astrocyte-mediated neuronal death in HIV-1 neuropathogenesis $(7,30)$. To further check the possibility of activity-dependent roles of coronin $1 \mathrm{~A}$, we checked whether HIV-1 Tat can modulate coronin $1 \mathrm{~A}$ expression in astrocytes. The real-time PCR assay and western blot analysis revealed a 1.46-fold and 1.43-fold increase in the level of coronin 1A mRNA and protein expression, respectively, in astrocytes transfected with HIV-1 Tat expression vector compared to cells transfected with vehicle control $(p<0.0005)$ (Fig. 4a, b). To validate this finding even further, immunohistochemistry was performed on the human brain autopsy sections. Coronin $1 \mathrm{~A}$ was found to be upregulated by 1.4 -fold $(p<0.05)$ in hippocampal sections of HIV-1 positive individuals as compared to their age-matched controls (Fig. 4c, d). To confirm the presence of astrocytes in the sections, GFAP staining was performed in the serial sections. Astrocytes were indeed found to be present in the hippocampal section, as clear from the parallel images taken for Coronin 1A and GFAP from the similar areas of the serial hippocampal sections (Supplementary Figure S4, Additional File 1).

HIV-1 Tat, indeed, turned the resting state astrocytes reactive as the cells showed enhanced expression of GFAP (1.66-fold; $p<0.005)$ (Fig. 4e) and pro-inflammatory gens such as VCAM1 (1.39-fold; $p<0.0005$ ), ICAM1 (1.2-fold; $p<0.005)$, PTGS2 (2.11-fold, $p<0.05)$ and NOS2 (1.59-fold; $p<0.05)$ (Fig. 4f). These findings, in conjunction with the previous results, further indicate that with the increase in its expression in the inflammatory environment, coronin $1 \mathrm{~A}$ might be involved in astrocyte reactivity and glia-mediated neurodegeneration. 


\section{Downregulation of coronin 1A attenuates HIV-1 Tat-induced GFAP, IL-6, and Glutamate release from astrocytes and supports Neuronal survival}

Next, we hypothesized if coronin $1 \mathrm{~A}$ is important for calcium mobilization and the literature suggests that calcium plays a key role in astrocyte activity and reactivity $(14,31)$, downregulating coronin $1 \mathrm{~A}$ might attenuate the detrimental effects of reactive astrocytes observed in various neuroinflammatory contexts, including neuroAIDS. So, to investigate this hypothesis, astrocytes were knocked down using siRNA against coronin $1 \mathrm{~A}$ for $48 \mathrm{~h}$ followed by transfection with HIV-1 Tat expression vector for $24 \mathrm{~h}$. Quantitative PCR and western blotting analyses revealed that the Tat-induced expression of GFAP attenuated in the experimental group where coronin $1 \mathrm{~A}$ was downregulated before-hand. Scrambled + HIV-1 Tat group showed a 1.51-fold $(p<0.0005)$ increase in GFAP levels, whereas coronin 1A siRNA + Tat group showed GFAP expression similar to the scrambled + vector control group (Fig. 5a; left and right panel). Astrocytes have also been reported to be immunocompetent and possess immunological properties (32). To check the immune status of the cells, mRNA levels of several pro-inflammatory genes were also checked in the current setting. Downregulating coronin $1 \mathrm{~A}$ could attenuate the levels of some of the Tat-induced pro-inflammatory genes (refer Fig. 4). It was observed that the scrambled + HIV-1 Tat group showed up-regulation in PTGS2 (1.67-fold, $p<0.05)$, NOS2 (1.73-fold, $p<0.05)$ whereas coronin $1 \mathrm{~A}$ siRNA + Tat group had PTGS2 and NOS2 levels similar to the scrambled + vector control group (Fig. 5b).

Reactive astrocytes release excess glutamate, cytokines, and/or chemokines which may cause excitotoxicity or neurotoxicity to the neurons present in the vicinity $(5,32-34)$. In this regard and to validate the findings of the previous experiments, several functional assays were performed using the conditioned-media derived from astrocytes after coronin 1A knockdown for $48 \mathrm{~h}$ followed by HIV-1 Tat transfection for $24 \mathrm{~h}$. The freshly collected cell supernatants were analyzed for the levels of released Interleukin-6 (IL-6) and glutamate. The FACS analysis supported the hypothesis even further as it was observed that the enhanced release of the pro-inflammatory cytokine, IL- 6 observed under the effect of HIV-1 Tat (1.17-fold, $p<0.05)$, attenuated when the cells were knocked down for coronin 1A, beforehand (Fig. 6a). Also, the glutamate release assay revealed that the HIV-1 Tat could not induce the enhanced glutamate release when the cells were knocked down for coronin 1A. HIV-1 Tat alone could indeed cause a 1.24 -fold $(p<0.05)$ increase in the levels of released glutamate (Fig. 6 b).

The deleterious effects of HIV-1 Tat-induced reactive astrocytes are also manifested in the form of neuronal death. So, to further investigate whether HIV-1 Tat-induced reactive astrocyte-mediated neuronal death could be attenuated by downregulating coronin $1 \mathrm{~A}$, we transfected astrocytes with coronin $1 \mathrm{~A}$ siRNA for $48 \mathrm{~h}$ followed by transfection with the HIV-1 Tat expression vector for $24 \mathrm{~h}$. Astrocyteconditioned media (ACM) were collected from these experimental sets and added to the neuronal cultures to inspect the indirect effects. ACM from the Tat alone group decreased neuronal survival to $75.5 \%$ $(p<0.05)$ whereas ACM collected from the group which was transfected with coronin 1A siRNA before HIV1 Tat transfection, showed rescue in neuronal death (Fig. 6c). These results signified that downregulating coronin $1 \mathrm{~A}$ is protective as it slows astrocyte reactivity and thus supported our hypothesis that coronin $1 \mathrm{~A}$ facilitates HIV-1 Tat-induced astrocyte reactivity and subsequent neuronal death. 


\section{miR-92b-5p regulates coronin $1 \mathrm{~A}$ in HIV-1 Tat-induced reactive astrocytes}

HIV-infected brains or brain cells also present a dysregulated cellular miRNA profile which might contribute to the virus-induced neurological complications (35-37). To check the miRNA regulatory machinery, a small RNA sequencing was outsourced which was performed on astrocytes transfected with HIV-1 Tat expression vector or vector control. A heat map was generated for the miRNAs which were differentially regulated (by \pm 1.3 to \pm 2.5 -fold) under the effect of HIV-1 Tat. Heatmap function of display 'R' tool (https://www.displayr.com) was used to generate the heatmap by using fold-change derived from the absolute reads of the sequencing data (Supplementary Figure S5, Additional File 1). Out of all the differentially regulated miRNAs, we narrowed down to the downregulated ones, and further, bioinformatics tool miRWalk, was employed to filter down to miRNAs which are predicted to target 3' UTR of COR01A (Fig. 7a). Individual qPCR assay performed for these miRNAs confirmed the HIV-1 Tatinduced downregulation. It was observed that HIV-1 Tat downregulated miR-92b-5p the most (-1.57-fold, $p<0.0005)$ (Fig. 7b), hence further confirmatory assays were performed only for miR-92b-5p.

To confirm whether miR-92b-5p regulates COR01A, 111 bp long 3' UTR of COR01A was cloned in pMIRREPORT and was used along with mimic-92b-5p for co-transfection into Hela cells. Luciferase assay was performed following the manufacturer's protocol and relative luciferase units were measured after $24 \mathrm{~h}$ of transfection. It was observed that mimic-92b-5p reduced the luminescence by -1.85 -fold $(p<0.005)$ confirming that it indeed targets $3^{\prime}$ UTR of CORO1A (Fig. 7c).

To further validate the findings, mimic, and inhibitor against miR-92b-5p were employed. Mimic $92 b-5 p$ transfection into human astrocytes for $48 \mathrm{~h}$ followed by qPCR analysis revealed that miR-92b-5p level increased by 247 -fold $(p<0.05)$ compared to the cells transfected with mimic control (Fig. 8a). The transcript and protein levels of coronin 1A showed a significant decrease by -2.36 -fold $(p<0.0005)$ and -1.35 -fold $(p<0.005)$ respectively, because of the mimic-92b-5p transfection, compared to the control transfected group (Fig. 8b, c). In contrast, transfection of inhibitor against miR-92b-5p resulted in significant inhibition of miR-92b-5p levels $(-2.33$-fold, $p<0.05)$ compared to the control group (Fig. $8 d)$. The transcript and the protein levels of coronin 1A showed a significant increase by 1.6 -fold $(p<0.05)$ and 1.57 -fold $(p<0.0005)$ respectively, because of the transfection with an inhibitor against miR-92b-5p, compared to the control group (Fig. 8e, f).

\section{Discussion}

Despite being heavily explored, the context-dependent behavior of astrocytes is yet to be thoroughly understood. Apart from performing many supportive roles, these cells exhibit varied behavior in pathophysiological conditions. Astrocyte reactivity is a common phenomenon in a variety of neurological disorders $(1,3)$. The reactive astrocytes become neuroinflammatory in several contexts and thus become detrimental for the neurons present in the vicinity, and hence cause mild to severe neuronal death. Reactive astrocyte-mediated neuronal death is a leading cause of neuronal loss observed in various neurological disorders including neuroAIDS. NeuroAIDS encompasses the neurological complications 
associated with HIV-1 infected individuals, around $50 \%$ of such individuals manifest some degree of HIV1 associated neurocognitive disorder (HAND) (38-40).

Calcium excitability of astrocytes is a well-established phenomenon in the field of glia biology. In fact, Calcium regulates astroglial secretions including glutamate $(14,27,31)$. Hence, it plays a central role in inducing astroglial activity both in physiological as well as pathophysiological conditions.

Coronin $1 \mathrm{~A}$ has been found to regulate $\mathrm{T}$ cell differentiation and activation events (20), it also regulates their survival by mediating calcium mobilization (23) and links cytoskeletal dynamics to receptor signaling $(21,26)$. In the brain, it has been found to influence NGF-TrkA endosomal trafficking as well as the signaling events. Also, by promoting cAMP/PKA signaling, it regulates synaptic plasticity and hence influences cognition and behavior $(22,41)$. The role of this protein in different cell types and whether its functions are context-dependent still needs extensive exploration. Astrocytes, indeed, play significant roles in regulating neuronal activity and astrocyte reactivity directly influences neuronal health and functioning in pathological contexts. Whether these cells express coronin $1 \mathrm{~A}$, and what role it plays is not known at all. To address this, and to identify the roles of this protein in different cell types and contexts, we investigated the role of coronin 1A in astrocyte physiology, and the astrocyte reactivity observed in the presence of a potent neurotoxicant HIV-1 Tat B. For the current study, we used a well-characterized model of primary astrocytes and neurons that were differentiated from human fetal brain-derived neural precursor cells.

Coronin 1A has mostly been studied in cells of hematopoietic origin, so, at first, we checked for the coronin $1 \mathrm{~A}$ expression in various brain cell types such as neural precursor cells (NPCs), astrocytes, and neurons; Jurkat T cells were taken as a positive control. All the brain cell types were found to express coronin 1A. Immunocytochemistry performed to confirm the intracellular localization of coronin 1A in astrocytes revealed its expression throughout the cytoplasm of the cell. Coronin $1 \mathrm{~A}$ expression was also validated on human brain autopsy sections (Fig. 1). The astrocytic culture was found to be positive for GFAP and Vimentin in more than $95 \%$ of the cells (Supplementary Figure S1, Additional File 1).

To explore the functions of this protein in resting-state astrocytes, we deployed a siRNA-mediated loss-offunction approach. A $48 \mathrm{~h}$ of knockdown was carried out and the cells were then assessed for knockdown efficiency and the transcript and protein levels of GFAP and Vimentin. This experiment led us to an important conclusion that coronin $1 \mathrm{~A}$ was dispensable in the resting-state astrocytes as the knockdown does not affect the GFAP and vimentin protein levels (Fig. 2). GFAP mRNA, although was found to be slightly affected but there was no substantial change in the protein levels. Also, the above experimental condition did neither alter the cell-proliferation nor the cell-viability (Supplementary Figure S2, Additional File 1). In general, the above results indicate that coronin 1A downregulation does not affect the resting-state astrocytes. Though the scope of this study was limited and focused on human primary astrocytes, generating a cell line lacking coronin 1A, to assess loss-of-function and/or reexpressing siRNA-resistant form of coronin $1 \mathrm{~A}$, may provide a wider window for manipulation-based studies. Such approaches can be utilized in the future by researchers of similar interests and are beyond 
the scope of the current study. The literature about the role of this protein in T cell activation $(20,23)$ provided us the momentum to investigate its involvement, if any, in stimulated conditions.

Astrocytes possess calcium excitability and gliotransmitters such as ATP, glutamate can stimulate astrocytes and cause calcium mobilization followed by downstream calcium signaling (27-29). To explore whether coronin 1A plays activity-dependent roles, we measured ATP-induced calcium mobilization. Interestingly, we found that coronin 1A knockdown compromised the calcium mobilization significantly, especially when the extracellular buffer used was devoid of $\mathrm{CaCl}_{2}$ i.e., when the source of calcium was only the intracellular stores (Fig. 3). To check what caused compromised calcium mobilization, we assessed the phosphorylation pattern of PLCY1, which is the most common and widely studied enzyme involved in calcium signaling. Astrocytes knocked down for coronin $1 \mathrm{~A}$ were stimulated with ATP for several time-points and further harvested to check the phosphorylation pattern of PLCY1. PLCY1 phosphorylation was found to be, although similar at $t=0 \mathrm{sec}$, but affected at later time-points of ATP stimulation, especially at $t=120 \mathrm{sec}$. Although it is not very strong evidence, this gave us a hint that this enzymatic pathway might have been affected and can be the cause of the compromised calcium mobilization. Such observations, however, demand detailed assessments of several enzymes involved in calcium signaling and are beyond the scope of the current study. We also assessed ERK1/2 phosphorylation, which is downstream to $\mathrm{Ca}^{2+}$, and it showed slightly compromised phosphorylation, but the differences were not significant (Supplementary Figure S3, Additional File 1). The compromised $\mathrm{Ca}^{2+}$ flux upon ATP-stimulation indicated the activity-dependent roles of coronin $1 \mathrm{~A}$ in astrocytes and therefore prompted us to look for its involvement in astrocyte reactivity.

HIV-1 Tat is a potent neurotoxicant and is known to induce astrocyte reactivity, which is characterized by an increase in GFAP expression (7), it also elevates the expression of cell adhesion molecules such as VCAM- 1 and ICAM- 1 in astrocytes $(42,43)$ and thus can facilitate the entry of inflammatory cells into the CNS. HIV-1 Tat also induces the expression of inducible nitric oxide synthase (iNOS) and Cyclooxygenase (COX)-2, an enzyme involved in prostanoid synthesis, which further modulates the expression of several inflammatory cytokines, and chemokines $(44,45)$. In agreement with the above-mentioned reports, we found enhanced expression of GFAP in human astrocytes transfected with HIV-1 Tat expression vector, which confirmed the reactive status of these cells. Also, HIV-1 Tat was found to enhance the mRNA levels of several pro-inflammatory genes such as VCAM-1, ICAM-1, PTGS2, and NOS2. Interestingly, these reactive astrocytes also exhibited the enhanced expression of coronin $1 \mathrm{~A}$, which further pointed out its activity-dependent roles. Validating the enhanced expression of coronin 1A on human brain autopsy sections supported our hypothesis even more (Fig. 4). Additionally, serial sections stained for GFAP confirmed the presence of astrocytes in the same region of the hippocampal sections (Supplementary Figure S4, Additional File 1).

If coronin $1 \mathrm{~A}$ has activity-dependent roles, then it might also be involved in the astrocyte reactivity observed in the presence of HIV-1 Tat. Hence, to explore whether it really facilitates astrocyte reactivity, HIV-1 Tat expression vector was transfected in cells downregulated for coronin $1 \mathrm{~A}$, sequentially. It was indeed observed that HIV-1 Tat-induced astrocyte reactivity, assessed by measuring levels of GFAP and 
some pro-inflammatory genes, PTGS2, and NOS2, diminished when the cells were downregulated for coronin 1A (Fig. 5). This propelled us to also assess the cell functionality by measuring the levels of release factors. Functional assessment performed on the conditioned-media revealed that downregulating coronin $1 \mathrm{~A}$ attenuated the deleterious outcomes of the reactive astrocytes such as the enhanced release of IL-6 and glutamate (Fig. 6). Cumulatively, the reduced inflammatory response further supported primary neurons, as the neuronal survival was found to be improved in the group treated with conditioned media collected from reactive astrocytes downregulated for coronin 1A (Fig. 6). This confirmed our hypothesis of the involvement of coronin 1A in facilitating HIV-1 Tat-induced astrocyte reactivity.

A closer look at the results obtained from the sequential transfection of coronin 1A siRNA followed by transfection of HIV-1 Tat expression vector, point out that downregulating coronin $1 \mathrm{~A}$ only (compare blue bars) pushes the cells towards resting-state. Downregulating coronin 1A suppressed the levels of PTGS2 transcripts and released IL-6 (Fig. 5 and 6, respectively). This effect also reflected in the neuronal survival assessment where the neurons treated with conditioned media collected from astrocytes downregulated for coronin $1 \mathrm{~A}$, survived even better than the control group (although not significant). The mechanisms causing these effects, require in-depth exploration in future studies.

Micro-RNAs dysregulated under the effect of HIV-1 often contribute to HIV-1 neuropathogenesis (35-37). Small RNA sequencing data gave us the pool of HIV-1 Tat-induced dysregulated miRNAs (Supplementary Figure S5, Additional File 1). We further narrowed down to a list of miRNAs that are downregulated under the effect of HIV-1 Tat and target the COR01A 3' UTR. The expression of short-listed miRNAs was assessed in the cells transfected with HIV-1 Tat expression vector, using real-time PCR assay. Out of all the selected miRNAs, miR-92b-5p was found to be affected the most and hence it could act as the potential regulator of coronin $1 \mathrm{~A}$ expression in reactive astrocytes. Utilizing mimic and inhibitor against miR-92b-5p to assess its binding with COR01A 3' UTR followed by measuring protein expression further confirmed the involvement of miR-92b-5p in regulating coronin 1A expression in the HIV-1 Tat-induced reactive astrocytes. Mimic-92b-5p significantly reduced the luciferase activity obtained when COR01A 3' UTR was cloned in the PMIR vector having luciferase gene. The mimic also decreased the transcript and protein levels of coronin 1A. In contrast, inhibitor-92b-5p increased the transcript and the protein levels of coronin $1 \mathrm{~A}$ (Fig. 7 and 8). This confirmed that miR-92b-5p mediated coronin $1 \mathrm{~A}$ regulation under the effect of HIV-1 Tat.

\section{Conclusions}

This study concludes that coronin $1 \mathrm{~A}$, although dispensable in resting-state astrocytes, facilitates calcium mobilization upon ATP stimulation in astrocytes. Coronin 1A expression is elevated in HIV-1 Tatinduced reactive astrocytes and the brain sections of HIV-1 infected individuals. Downregulating coronin $1 \mathrm{~A}$ attenuates the deleterious effects of reactive astrocytes and hence supports neuronal survival. miR92b-5p regulates coronin 1A expression by targeting its $3^{\prime}$ UTR. By reducing the levels of miR-92b-5p, HIV-

1 Tat might augment coronin $1 \mathrm{~A}$ protein levels which further facilitates astrocyte reactivity and astrocyte- 
mediated neuroinflammation. Hence, this study reports the non-canonical, activity-dependent roles of coronin $1 \mathrm{~A}$, in stimulated astrocytes, and in promoting HIV-1 Tat-induced astrocyte reactivity.

\section{Abbreviations}

NPC Neural precursor cells

PDA Progenitor-derived astrocytes

PDN Progenitor-derived neurons

GFAP Glial fibrillary acidic protein

ACM Astrocyte-conditioned media

ATP Adenosine triphosphate

IL-6 Interleukin-6

PLC Phospholipase C

VCAM1 Vascular cell adhesion molecule-1

ICAM1 Intercellular cell adhesion molecule-1

PTGS2 Prostaglandin-endoperoxide synthase-2

NOS2 Nitric oxide synthase-2

HIV-1 Human immunodeficiency virus -1

Tat Transactivator of transcription

AIDS Acquired immunodeficiency syndrome

HAND HIV-1 associated neurocognitive disorder

\section{Declarations}

\section{Ethics approval and consent to participate}

Human brain tissues collected from elective abortions with the informed consent of mothers, were processed as per the protocols laid down by the Institutional Human Ethics and Stem Cell Research Committee under strict compliance with the guidelines of ICMR, India. 
Not applicable

\section{Availability of data and materials}

All data generated or analyzed during this study are included in this published article [and its supplementary information files].

\section{Competing interests}

The authors declare that they have no competing interests.

\section{Funding}

The authors acknowledge the Research Fellowship to Hriday S Pandey and Bindu from CSIR, New Delhi, India; financial support to Prof. Pankaj Seth from Department of Biotechnology (DBT), Department of Science and Technology (DST), New Delhi and NBRC core, and project assistantship to Rishabh Kapoor from NBRC.

\section{Author's contributions}

HSP designed, performed experiments, analyzed, and interpreted the data, and formulated the manuscript. RK performed experiments and helped in analyzing data. Bindu helped in performing experiments. PS helped in designing experiments, analyzing data, and finalizing the manuscript. All authors read and approved the final manuscript.

\section{Acknowledgments}

Technical assistance from Mr. Naushad Alam and Mr. Durga Lal Meena throughout the study is highly appreciated. We appreciate Mr. S. D. Joshi for his assistance in immunohistochemistry. We wish to acknowledge Mrs. Manju Tewari and Mr. Vipendra Kumar Singh for their critical support in molecular experiments. HIV-1 Tat B expression vector, which was a kind gift from Prof. Udaykumar Ranga, JNCASR, India, is greatly appreciated. We are grateful to Human Brain Tissue Repository for Neurological Studies, Department of Neuropathology, National Institute of Mental Health and Neurosciences, Bangalore, India for providing the human brain autopsy sections. The authors also express their gratitude to Dr. Jean Pieters for sharing the coronin 1A antibody needed for some initial pilot experiments of the project. The authors wish to acknowledge the support of the facilities provided under the Biotechnology Information System Network (BTISNET) grant, Department of Biotechnology, India, and Computing Centre at NBRC, Manesar, India.

\section{References}

1. Sofroniew MV, Vinters HV. Astrocytes: biology and pathology. Acta neuropathologica. 2010;119(1):735. 
2. Pannasch $\mathrm{U}$, Rouach $\mathrm{N}$. Emerging role for astroglial networks in information processing: from synapse to behavior. Trends in neurosciences. 2013;36(7):405-17.

3. Pekny M, Pekna M, Messing A, Steinhauser C, Lee JM, Parpura V, et al. Astrocytes: a central element in neurological diseases. Acta neuropathologica. 2016;131(3):323-45.

4. Sofroniew MV. Molecular dissection of reactive astrogliosis and glial scar formation. Trends in neurosciences. 2009;32(12):638-47.

5. Farina C, Aloisi F, Meinl E. Astrocytes are active players in cerebral innate immunity. Trends in immunology. 2007;28(3):138-45.

6. Kaul M, Garden GA, Lipton SA. Pathways to neuronal injury and apoptosis in HIV-associated dementia. Nature. 2001;410(6831):988-94.

7. Zhou BY, Liu Y, Kim B, Xiao Y, He JJ. Astrocyte activation and dysfunction and neuron death by HIV-1 Tat expression in astrocytes. Mol Cell Neurosci. 2004;27(3):296-305.

8. Pandey HS, Seth P. Friends Turn Foe-Astrocytes Contribute to Neuronal Damage in NeuroAIDS. J Mol Neurosci. 2019;69(2):286-97.

9. Churchill MJ, Wesselingh SL, Cowley D, Pardo CA, McArthur JC, Brew BJ, et al. Extensive astrocyte infection is prominent in human immunodeficiency virus-associated dementia. Annals of neurology. 2009;66(2):253-8.

10. Gorry PR, Howard JL, Churchill MJ, Anderson JL, Cunningham A, Adrian D, et al. Diminished production of human immunodeficiency virus type 1 in astrocytes results from inefficient translation of gag, env, and nef mRNAs despite efficient expression of Tat and Rev. Journal of virology. 1999;73(1):352-61.

11. Carey AN, Sypek El, Singh HD, Kaufman MJ, McLaughlin JP. Expression of HIV-Tat protein is associated with learning and memory deficits in the mouse. Behavioural brain research. 2012;229(1):48-56.

12. Kim BO, Liu Y, Ruan Y, Xu ZC, Schantz L, He JJ. Neuropathologies in transgenic mice expressing human immunodeficiency virus type 1 Tat protein under the regulation of the astrocyte-specific glial fibrillary acidic protein promoter and doxycycline. The American journal of pathology. 2003;162(5):1693-707.

13. Bazargani N, Attwell D. Astrocyte calcium signaling: the third wave. Nature neuroscience. 2016;19(2):182-9.

14. Parpura V, Basarsky TA, Liu F, Jeftinija K, Jeftinija S, Haydon PG. Glutamate-mediated astrocyteneuron signalling. Nature. 1994;369(6483):744-7.

15. Mothet JP, Parent AT, Wolosker H, Brady RO, Jr., Linden DJ, Ferris CD, et al. D-serine is an endogenous ligand for the glycine site of the N-methyl-D-aspartate receptor. Proceedings of the National Academy of Sciences of the United States of America. 2000;97(9):4926-31.

16. Coco S, Calegari F, Pravettoni E, Pozzi D, Taverna E, Rosa P, et al. Storage and release of ATP from astrocytes in culture. The Journal of biological chemistry. 2003;278(2):1354-62. 
17. Fellin T, Pascual O, Gobbo S, Pozzan T, Haydon PG, Carmignoto G. Neuronal synchrony mediated by astrocytic glutamate through activation of extrasynaptic NMDA receptors. Neuron. 2004;43(5):72943.

18. Haughey NJ, Holden CP, Nath A, Geiger JD. Involvement of inositol 1,4,5-trisphosphate-regulated stores of intracellular calcium in calcium dysregulation and neuron cell death caused by HIV-1 protein tat. Journal of neurochemistry. 1999;73(4):1363-74.

19. Ferrari G, Langen $H$, Naito $M$, Pieters J. A coat protein on phagosomes involved in the intracellular survival of mycobacteria. Cell. 1999;97(4):435-47.

20. Nal B, Carroll P, Mohr E, Verthuy C, Da Silva MI, Gayet O, et al. Coronin-1 expression in T lymphocytes: insights into protein function during $T$ cell development and activation. International immunology. 2004;16(2):231-40.

21. Pieters J, Muller $P$, Jayachandran R. On guard: coronin proteins in innate and adaptive immunity. Nature reviews. 2013;13(7):510-8.

22. Jayachandran R, Liu X, Bosedasgupta S, Muller P, Zhang CL, Moshous D, et al. Coronin 1 regulates cognition and behavior through modulation of cAMP/protein kinase A signaling. PLoS biology. 2014;12(3):e1001820.

23. Mueller P, Massner J, Jayachandran R, Combaluzier B, Albrecht I, Gatfield J, et al. Regulation of T cell survival through coronin-1-mediated generation of inositol-1,4,5-trisphosphate and calcium mobilization after T cell receptor triggering. Nature immunology. 2008;9(4):424-31.

24. Foger N, Rangell L, Danilenko DM, Chan AC. Requirement for coronin 1 in T lymphocyte trafficking and cellular homeostasis. Science (New York, NY. 2006;313(5788):839-42.

25. Jayachandran R, Sundaramurthy V, Combaluzier $B$, Mueller $P$, Korf $H$, Huygen $K$, et al. Survival of mycobacteria in macrophages is mediated by coronin 1-dependent activation of calcineurin. Cell. 2007;130(1):37-50.

26. Mugnier B, Nal B, Verthuy C, Boyer C, Lam D, Chasson L, et al. Coronin-1A links cytoskeleton dynamics to TCR alpha beta-induced cell signaling. PloS one. 2008;3(10):e3467.

27. Verkhratsky A, Orkand RK, Kettenmann H. Glial calcium: homeostasis and signaling function. Physiol Rev. 1998;78(1):99-141.

28. Kirischuk S, Moller T, Voitenko N, Kettenmann H, Verkhratsky A. ATP-induced cytoplasmic calcium mobilization in Bergmann glial cells. J Neurosci. 1995;15(12):7861-71.

29. Hamilton N, Vayro S, Kirchhoff F, Verkhratsky A, Robbins J, Gorecki DC, et al. Mechanisms of ATPand glutamate-mediated calcium signaling in white matter astrocytes. Glia. 2008;56(7):734-49.

30. Tewari M, Monika, Varghse RK, Menon M, Seth P. Astrocytes mediate HIV-1 Tat-induced neuronal damage via ligand-gated ion channel P2X7R. Journal of neurochemistry. 2015;132(4):464-76.

31. Verkhratsky A, Nedergaard M. Physiology of Astroglia. Physiol Rev. 2018;98(1):239-389.

32. Dong Y, Benveniste EN. Immune function of astrocytes. Glia. 2001;36(2):180-90. 
33. Potter MC, Figuera-Losada M, Rojas C, Slusher BS. Targeting the glutamatergic system for the treatment of HIV-associated neurocognitive disorders. J Neuroimmune Pharmacol. 2013;8(3):594607.

34. John GR, Lee SC, Brosnan CF. Cytokines: powerful regulators of glial cell activation. Neuroscientist. 2003;9(1):10-22.

35. Tatro ET, Scott ER, Nguyen TB, Salaria S, Banerjee S, Moore DJ, et al. Evidence for Alteration of Gene Regulatory Networks through MicroRNAs of the HIV-infected brain: novel analysis of retrospective cases. PloS one. 2010;5(4):e10337.

36. Fatima M, Prajapati B, Saleem K, Kumari R, Mohindar Singh Singal C, Seth P. Novel insights into role of miR-320a-VDAC1 axis in astrocyte-mediated neuronal damage in neuroAIDS. Glia. 2017;65(2):25063.

37. Sardo L, Vakil PR, Elbezanti W, El-Sayed A, Klase Z. The inhibition of microRNAs by HIV-1 Tat suppresses beta catenin activity in astrocytes. Retrovirology. 2016;13:25.

38. Heaton RK, Clifford DB, Franklin DR, Jr., Woods SP, Ake C, Vaida F, et al. HIV-associated neurocognitive disorders persist in the era of potent antiretroviral therapy: CHARTER Study. Neurology. 2010;75(23):2087-96.

39. Sacktor N, Robertson K. Evolving clinical phenotypes in HIV-associated neurocognitive disorders. Curr Opin HIV AIDS. 2014;9(6):517-20.

40. Gannon P, Khan MZ, Kolson DL. Current understanding of HIV-associated neurocognitive disorders pathogenesis. Curr Opin Neurol. 2011;24(3):275-83.

41. Suo D, Park J, Harrington AW, Zweifel LS, Mihalas S, Deppmann CD. Coronin-1 is a neurotrophin endosomal effector that is required for developmental competition for survival. Nature neuroscience. 2014;17(1):36-45.

42. Woodman SE, Benveniste EN, Nath A, Berman JW. Human immunodeficiency virus type 1 TAT protein induces adhesion molecule expression in astrocytes. J Neurovirol. 1999;5(6):678-84.

43. Song HY, Ryu J, Ju SM, Park LJ, Lee JA, Choi SY, et al. Extracellular HIV-1 Tat enhances monocyte adhesion by up-regulation of ICAM-1 and VCAM-1 gene expression via ROS-dependent NF-kappaB activation in astrocytes. Exp Mol Med. 2007;39(1):27-37.

44. Liu X, Jana M, Dasgupta S, Koka S, He J, Wood C, et al. Human immunodeficiency virus type 1 (HIV1 ) tat induces nitric-oxide synthase in human astroglia. The Journal of biological chemistry. 2002;277(42):39312-9.

45. Flora G, Pu H, Hennig B, Toborek M. Cyclooxygenase-2 is involved in HIV-1 Tat-induced inflammatory responses in the brain. Neuromolecular Med. 2006;8(3):337-52.

\section{Figures}



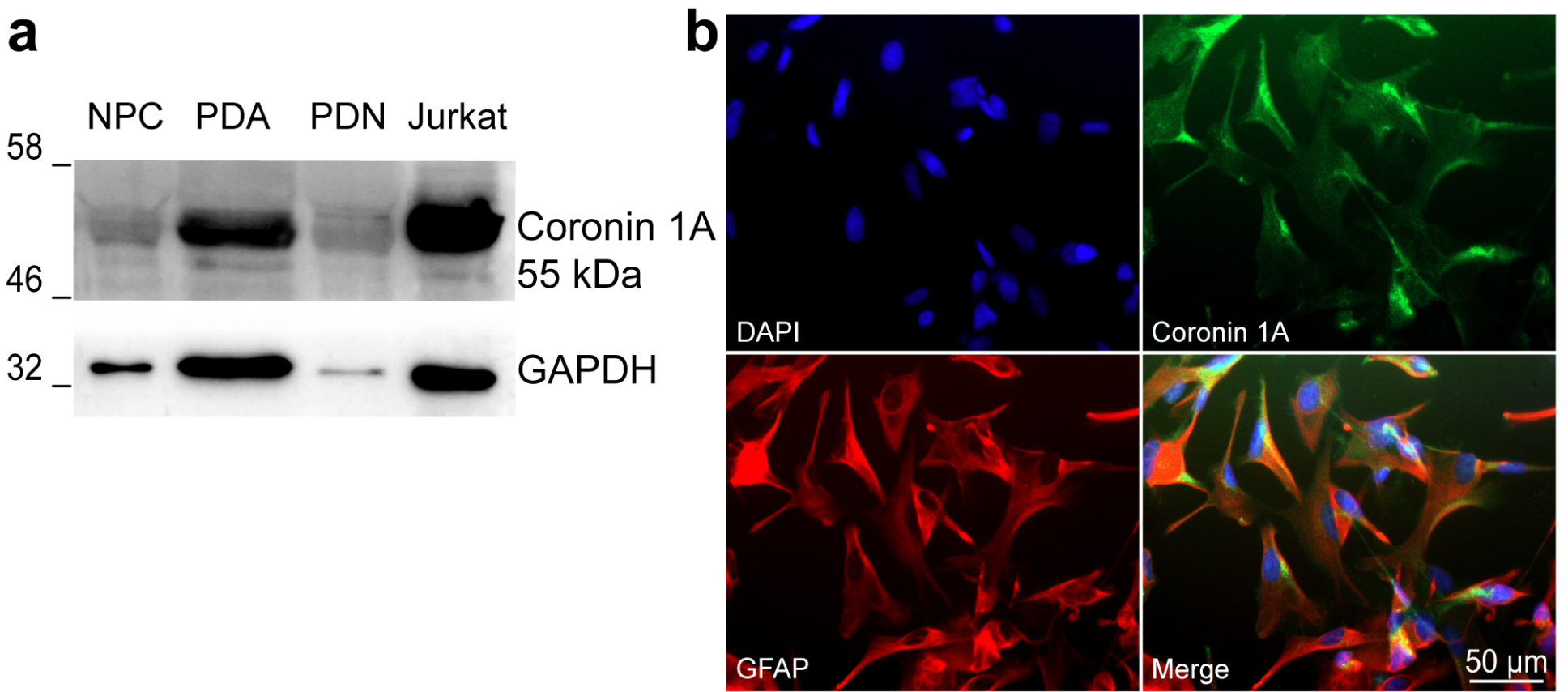

C
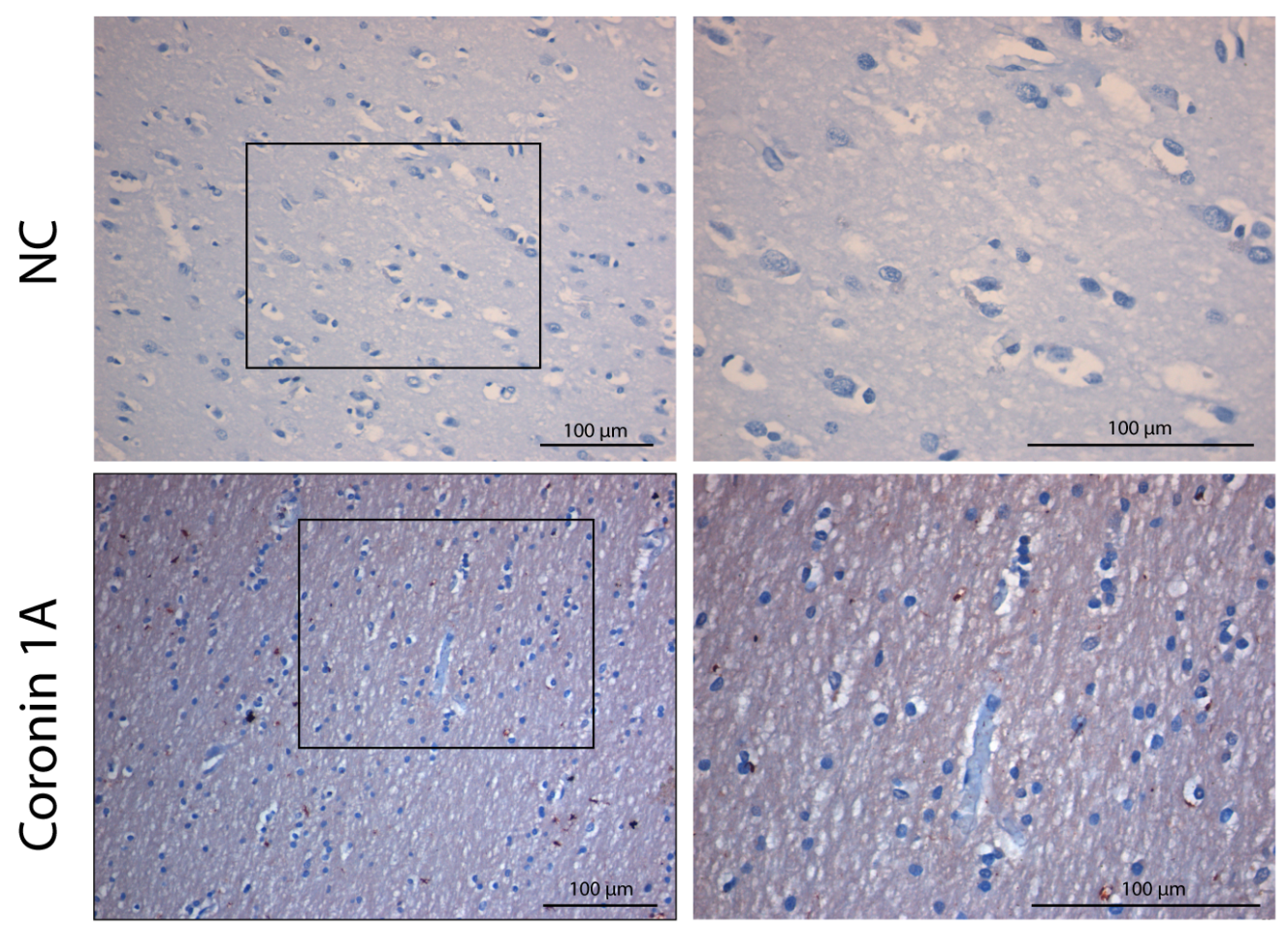

\section{Figure 1}

Coronin 1A expression in human brain cells and brain autopsy tissue. Coronin 1A protein expression in (a) neural progenitors, astrocytes, neurons, and Jurkat T cells and (b) Immunocytochemistry was performed on astrocytes immunolabeled for Coronin 1A (green), and GFAP (red). Cell nuclei were DAPI stained (blue). Images were acquired using a 20X objective lens and the scale bar represents $50 \mu \mathrm{m}$. (c) Immunohistochemistry was performed on human brain autopsy sections of the hippocampal region; the right panel shows the blown-up images of the inset marked in the left panel. Images were acquired using a 20X objective lens and the scale bar represents $100 \mu \mathrm{m}$. NPC=Neural precursor cells; PDA=Progenitorderived astrocytes; PDN=Progenitor-derived neurons; NC=Negative control for antibody. 


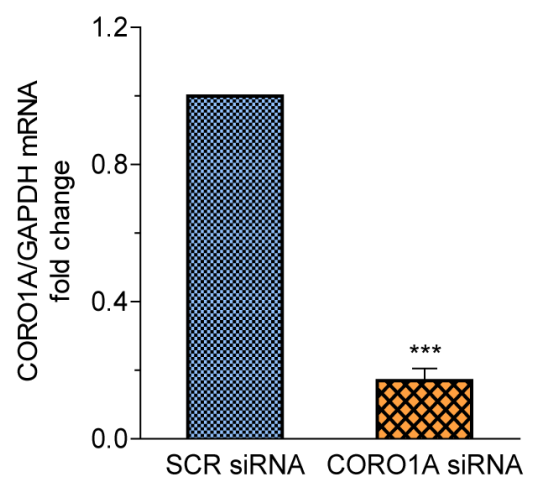

C

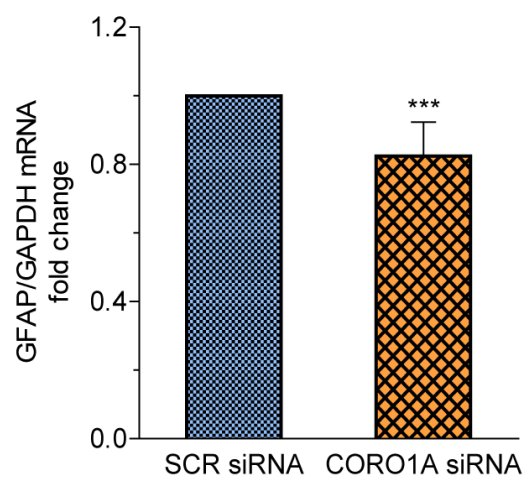

e

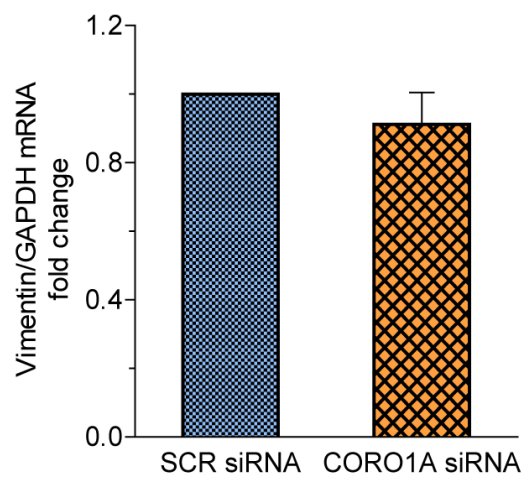

b

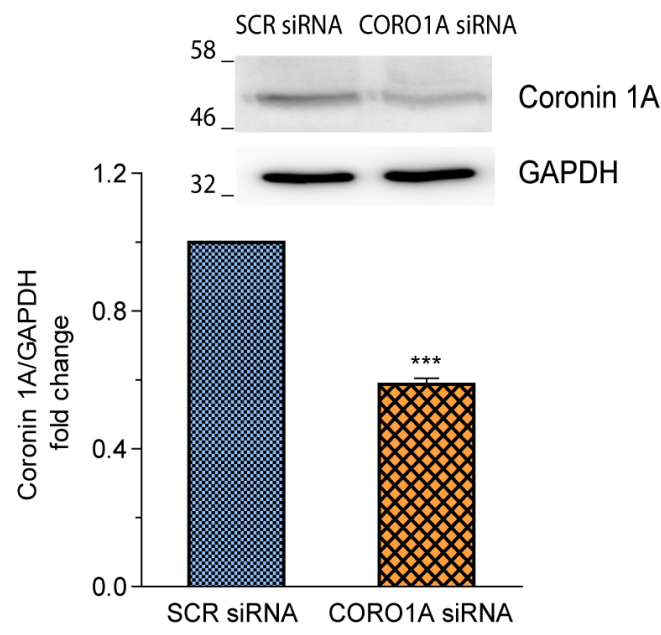

d

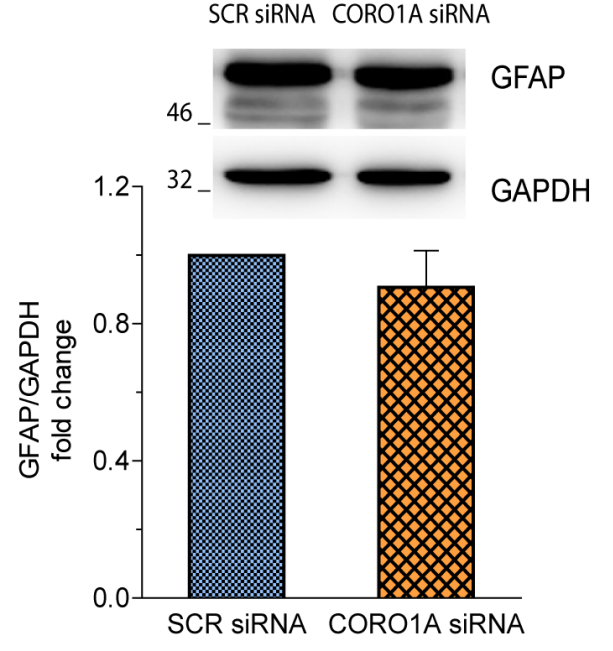

f

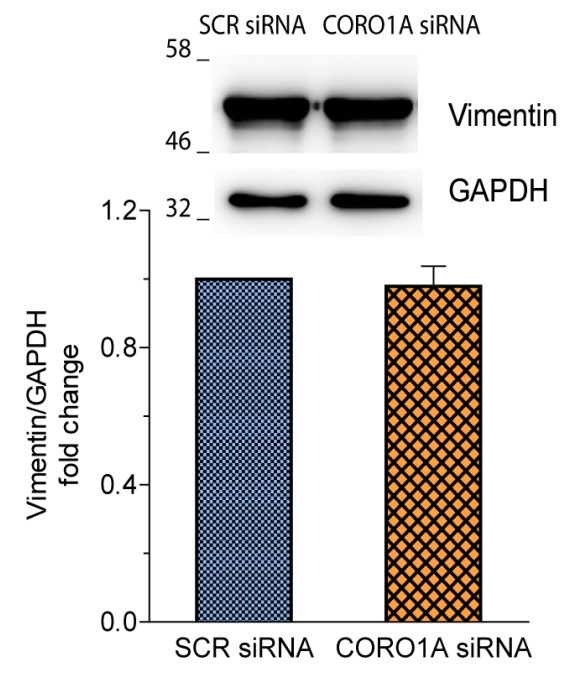

Figure 2

Coronin 1A knockdown does not affect the resting-state human astrocytes. Astrocytes were transfected with COR01A siRNA for $48 \mathrm{~h}$, harvested, and transcript and protein levels were analyzed using real-time qPCR western blotting, respectively. (a) The bar graph represents the fold change in coronin $1 \mathrm{~A}$ expression at mRNA and (b) protein, compared to the control group. Cells downregulated for coronin $1 \mathrm{~A}$ were assessed for (c) Glial Fibrillary Acidic Protein (GFAP) mRNA and (d) protein expression. Vimentin (e) 
mRNA and (f) protein expression was also assessed in the same experimental group. Blots are representative and the bar graph shows the densitometric analysis of the blots. GAPDH was used as a normalization control for all the analyses. Data represent mean \pm S.D of four independent experiments. *** represents $p<0.0005$. SCR=scrambled; COR01A=coronin $1 \mathrm{~A}$.

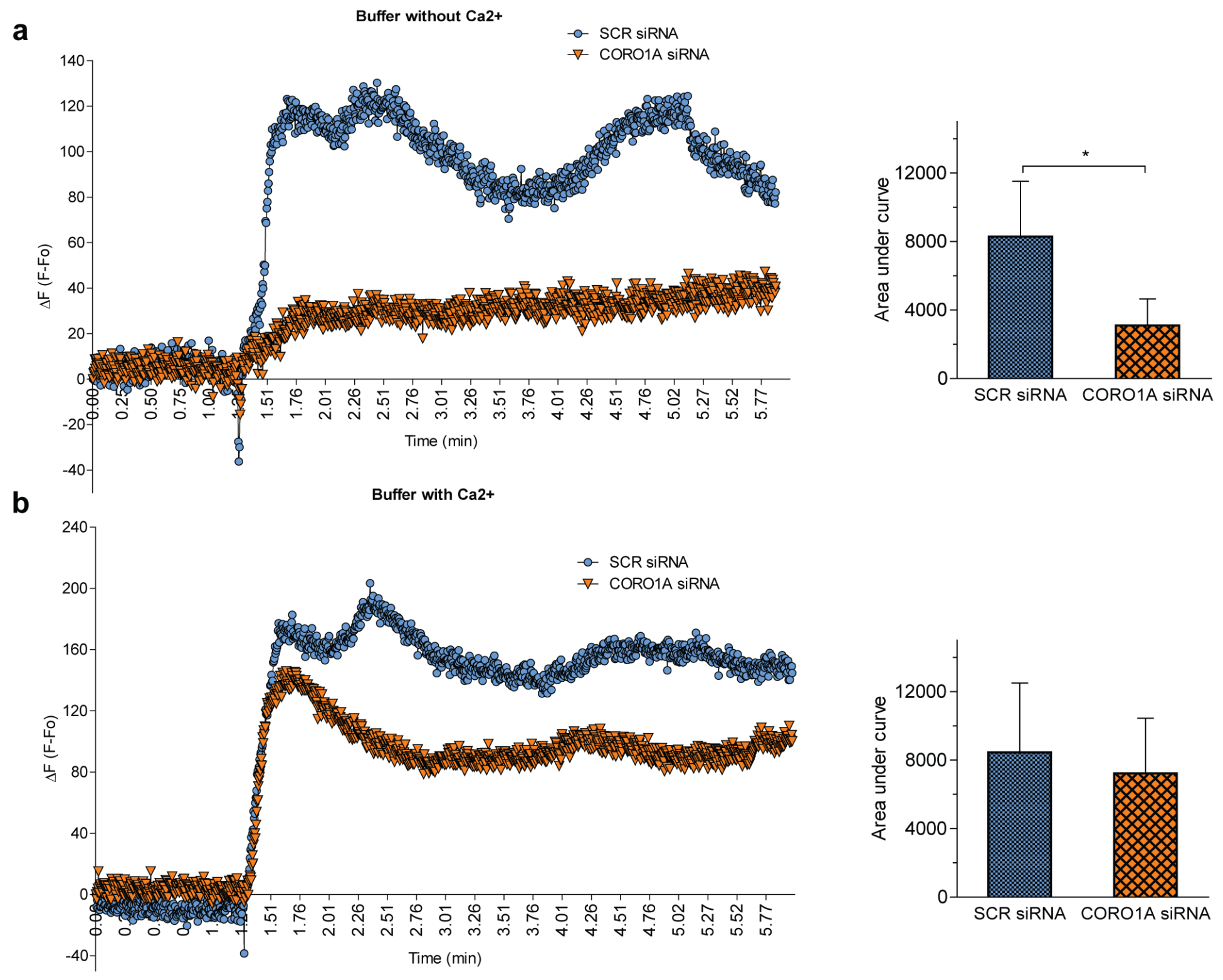

\section{Figure 3}

ATP-induced Calcium mobilization in human astrocytes downregulated for coronin 1A. Calcium mobilization in Fluo-4 AM labeled cells, knocked down for coronin 1A, upon stimulation with $10 \mu \mathrm{M}$ ATP in (a) HEPES buffer without $\mathrm{CaCl}$, and (b) HEPES buffer having $\mathrm{CaCl}$. Arrow indicates the time of the ATP application in the buffer. The bar graph (right panel) shows the area under the curve (AUC). Data represent mean \pm S.D of three independent experiments. * represents $p<0.05$. SCR=scrambled; $\operatorname{COR01A}=$ coronin $1 \mathrm{~A}, \Delta \mathrm{F}=$ change in fluorescence intensity. 

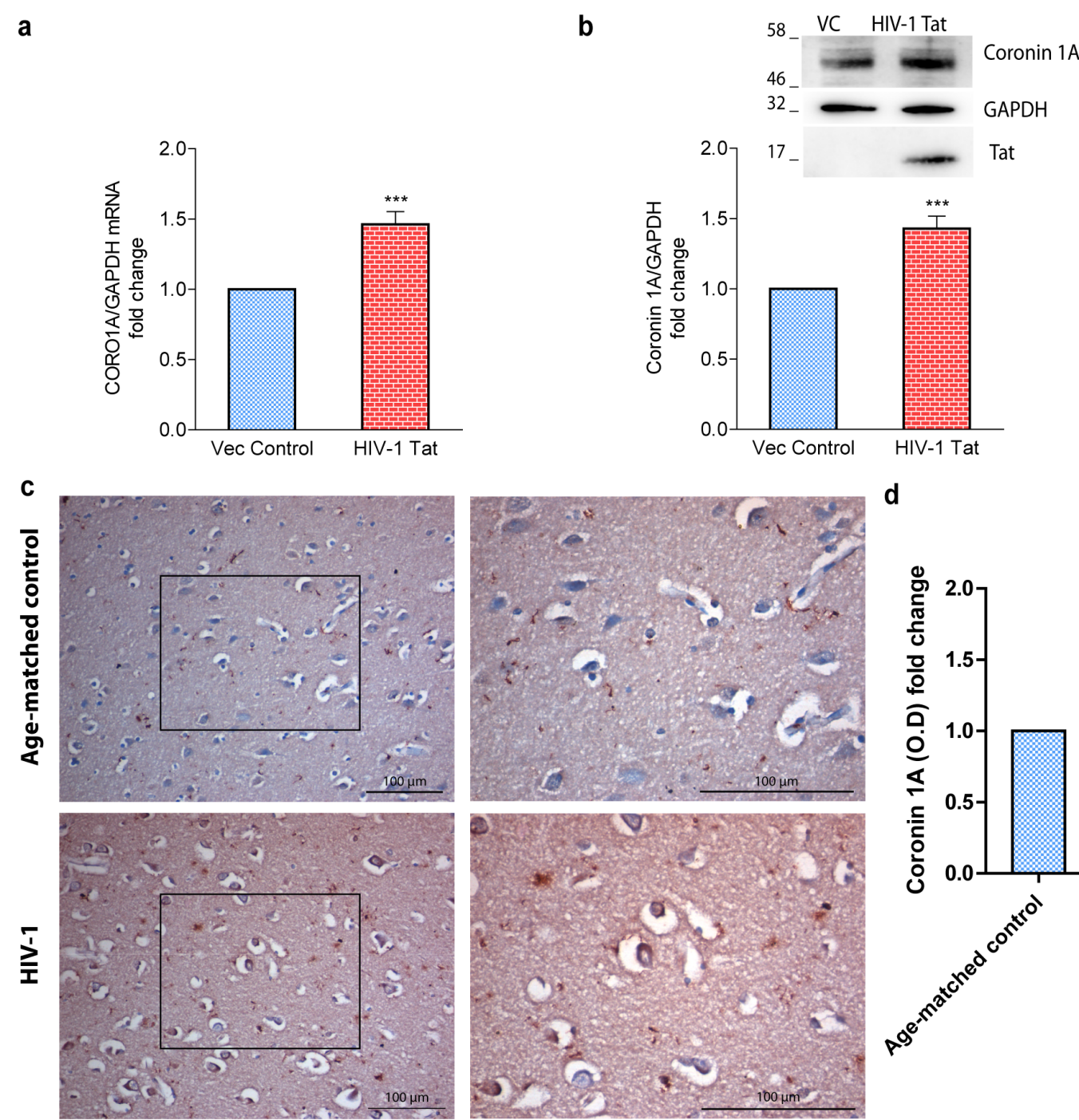

d
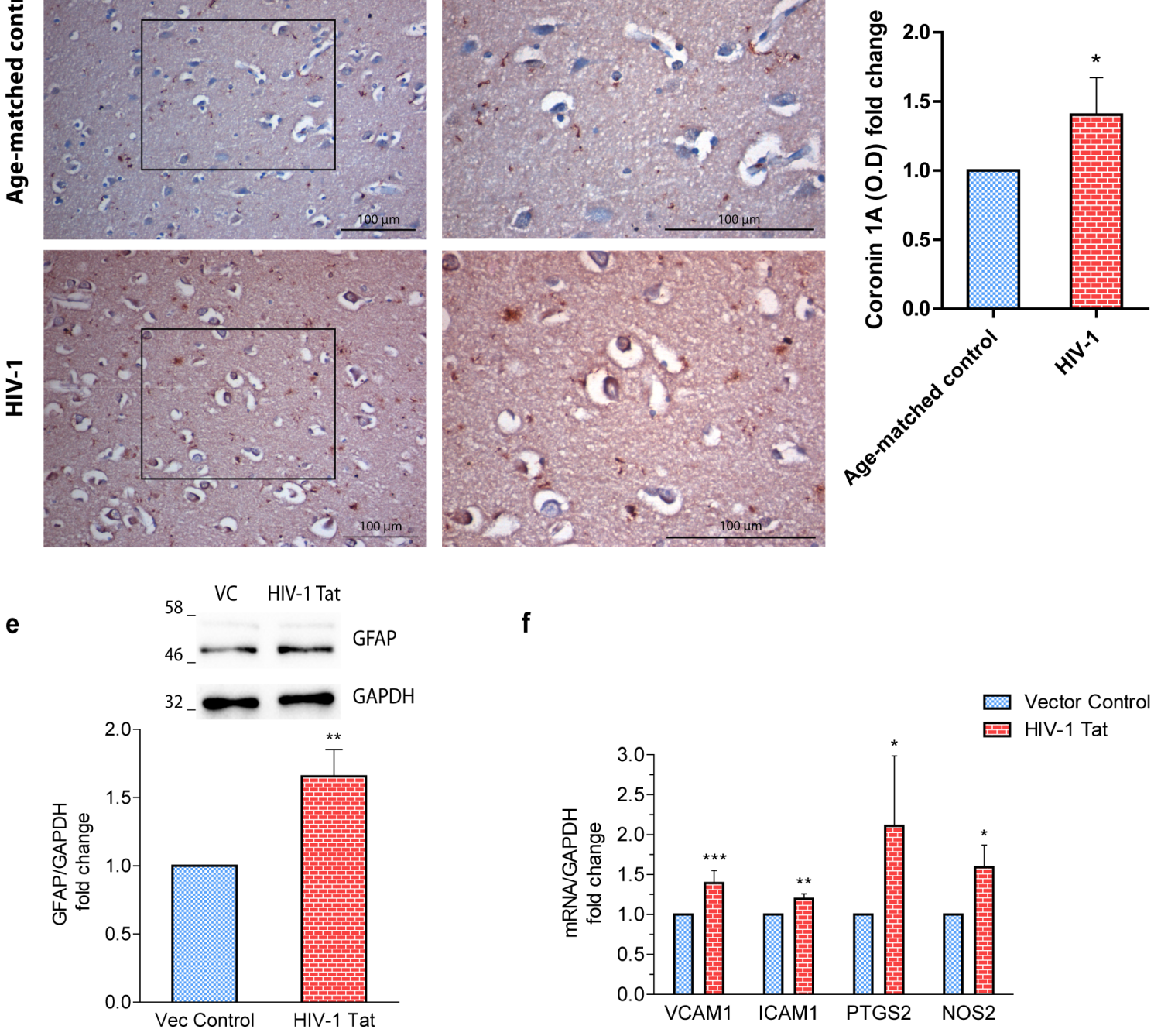

Figure 4

HIV-1 Tat augments coronin 1A expression in the brain and induces astrocyte reactivity. Astrocytes transfected with HIV-1 Tat expression vector for $24 \mathrm{~h}$ were harvested and analyzed for (a) Coronin $1 \mathrm{~A}$ mRNA levels, using real-time PCR assay and (b) protein level, using western blotting, the upper panel shows the representative blots and the lower panel shows the densitometric analysis of the same, compared to cells transfected with vector control. (c) Representative images of immunohistochemistry 
performed for coronin 1A on human brain autopsy sections of the hippocampal region of HIV-1 patients and their age-matched controls; right panel shows the blown up images of the inset marked in the left panel and (d) bar graph shows the fold change in coronin 1A optical density in the IHC images. Images were acquired using a 20X objective lens and the scale bar represents $100 \mu \mathrm{m}$. The reactive status of the HIV-1 Tat transfected cells was checked by assessing the expression of (e) GFAP protein and (f) proinflammatory genes viz VCAM1, ICAM1, PTGS2, and NOS2 compared to the group transfected with vector control. GAPDH was used as a normalization control for all the analyses. Data represents mean \pm S.D of three (for IHC) to four independent experiments. * represents $p<0.05,{ }^{* \star} p<0.005$, and ${ }^{\star \star \star} p<0.0005$. $\mathrm{VC}=$ vector control; O.D=optical density.

a
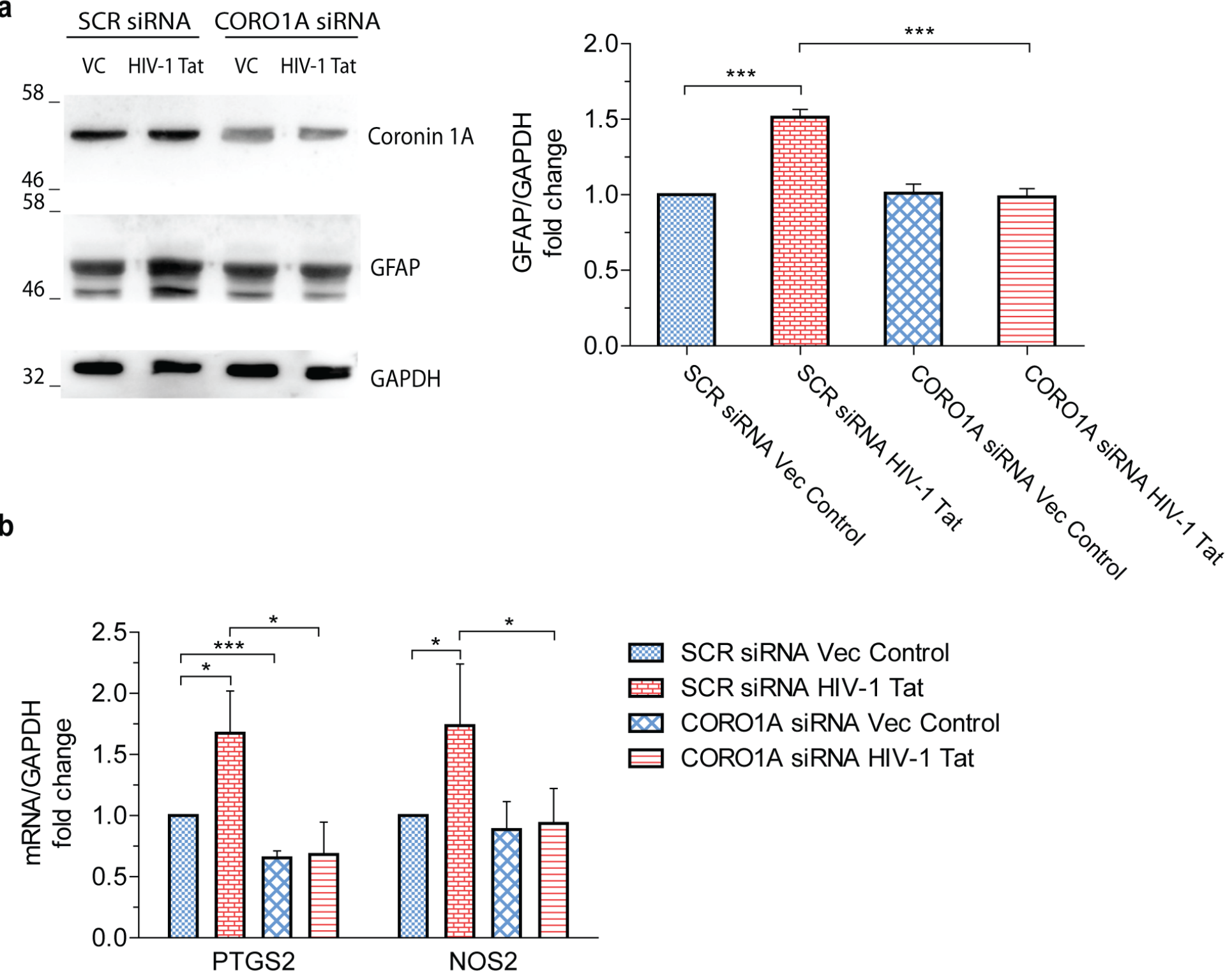

SCR siRNA Vec Control

圖 SCR siRNA HIV-1 Tat

Q CORO1A siRNA Vec Control

曰 CORO1A siRNA HIV-1 Tat

Figure 5

Coronin 1A downregulation attenuates expression of HIV-1 Tat-induced GFAP and pro-inflammatory genes in reactive astrocytes. Human astrocytes downregulated for coronin $1 \mathrm{~A}$ using siRNA for $48 \mathrm{~h}$ followed by transfection with HIV-1 Tat for $24 \mathrm{~h}$, were harvested and analyzed for (a) GFAP protein 
expression, using western blotting. The left panel shows representative blot and the right panel shows the densitometric analysis of the same and (b) pro-inflammatory genes viz PTGS2 and NOS2, using real-time PCR assay. GAPDH was used as a normalization control for all the analyses. Data represents mean \pm S.D of three independent experiments. ${ }^{*} p<0.05,{ }^{* \star *} p<0.0005$. SCR=scrambled; COR01A=coronin $1 \mathrm{~A}$.

a

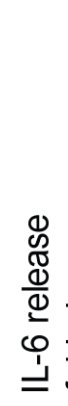

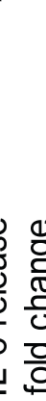
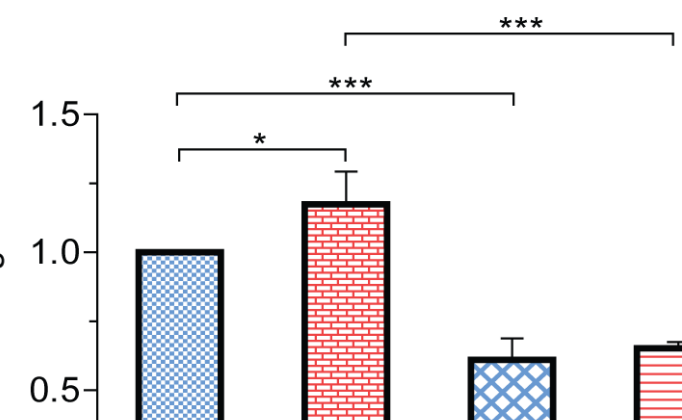

1.5
0.5
0.0

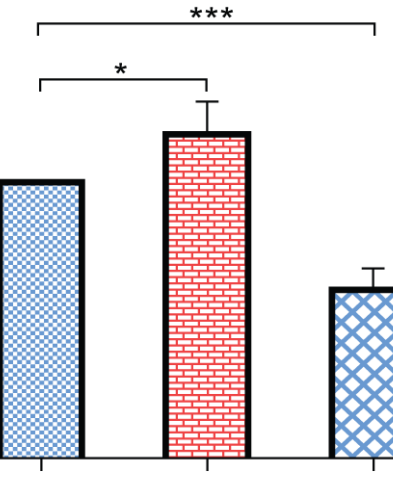
${ }^{S} \mathrm{P}$

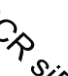

b

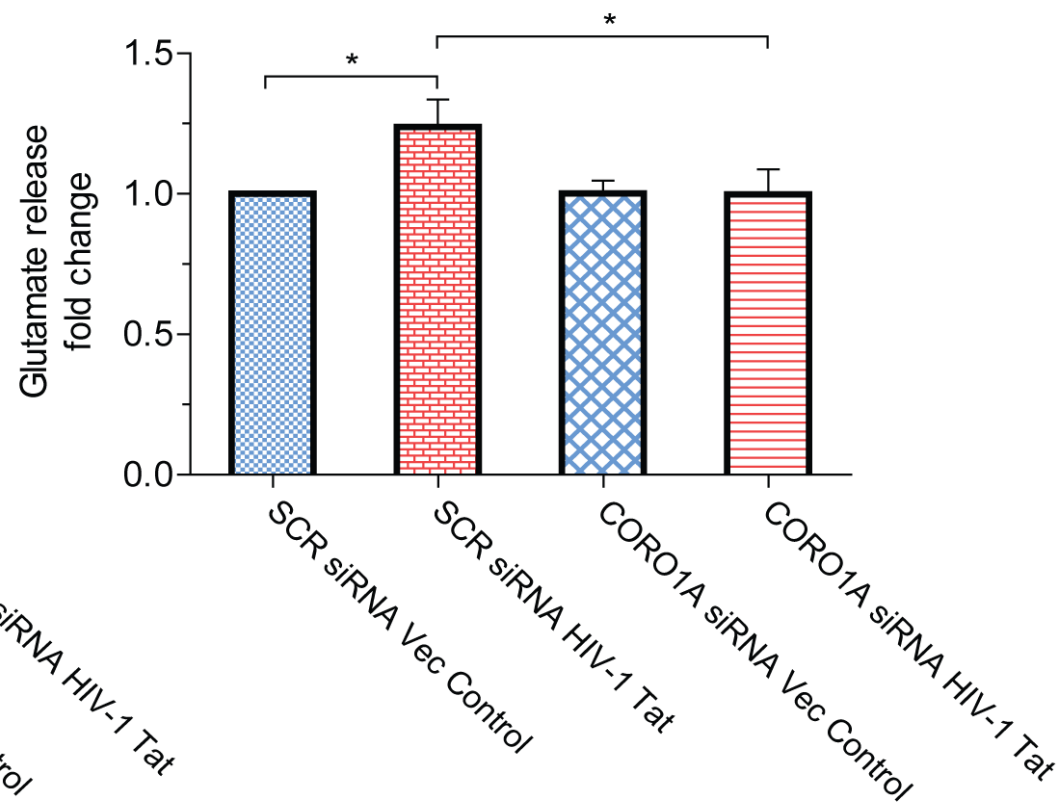

\section{C}

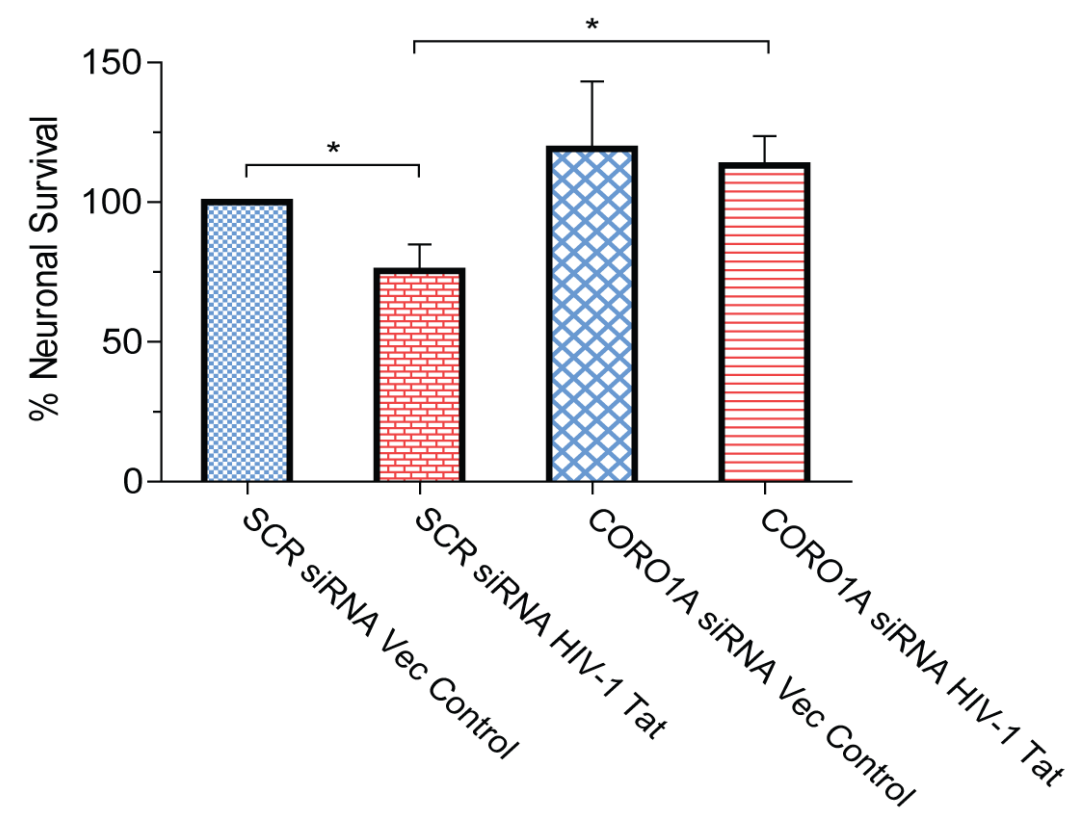

Figure 6

Downregulation of Coronin 1A attenuates HIV-1 Tat-induced release of IL-6, glutamate, and associated indirect-neuronal death. Astrocyte-conditioned media (ACM) collected from cells, transfected with COR01A siRNA for $48 \mathrm{~h}$ followed by transfection with HIV-1 Tat expression vector for $24 \mathrm{~h}$, were analyzed for released (a) interleukin-6 (IL-6), using Flow cytometry and (b) glutamate, using enzyme kinetics based glutamate release assay. Human primary neurons were treated with ACM collected from the above 
experiment for $24 \mathrm{~h}$ and assessed for (c) Neuronal survival by analyzing the TUNEL-positive neuronal cells. Data represent the mean \pm S.D of three independent experiments. ${ }^{*} p<0.05$ with respect to control. SCR=scrambled; CORO1A=coronin $1 \mathrm{~A}$.

a

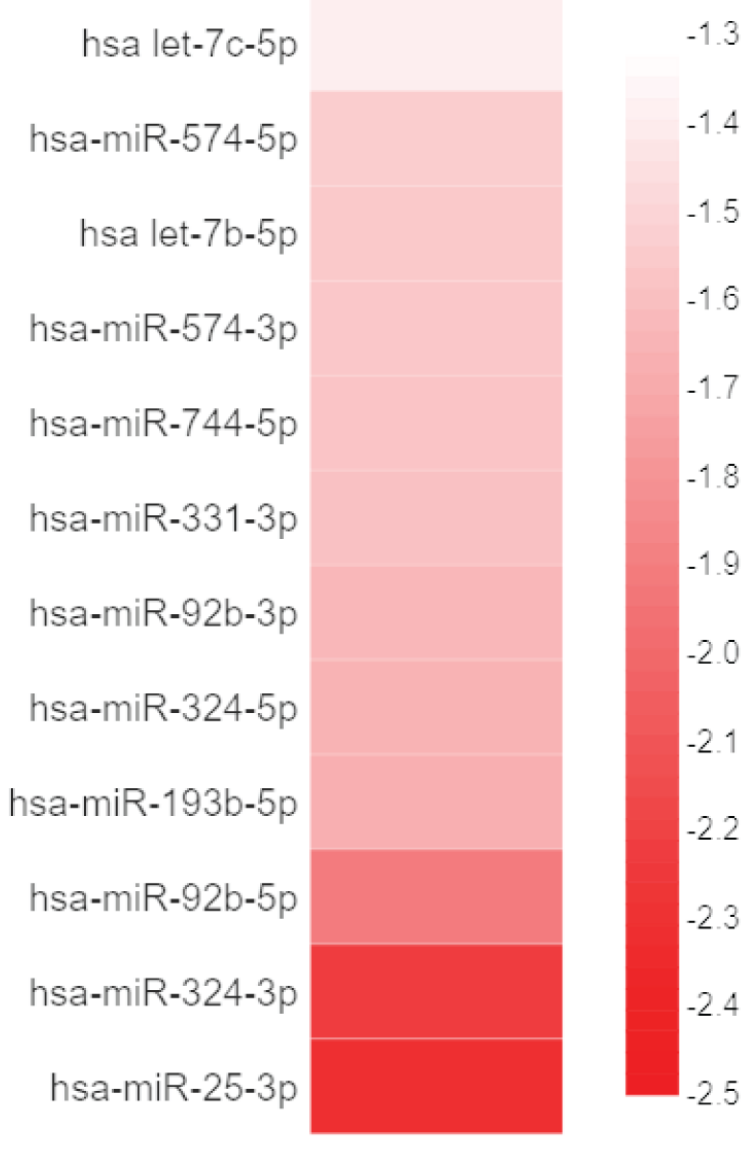

b
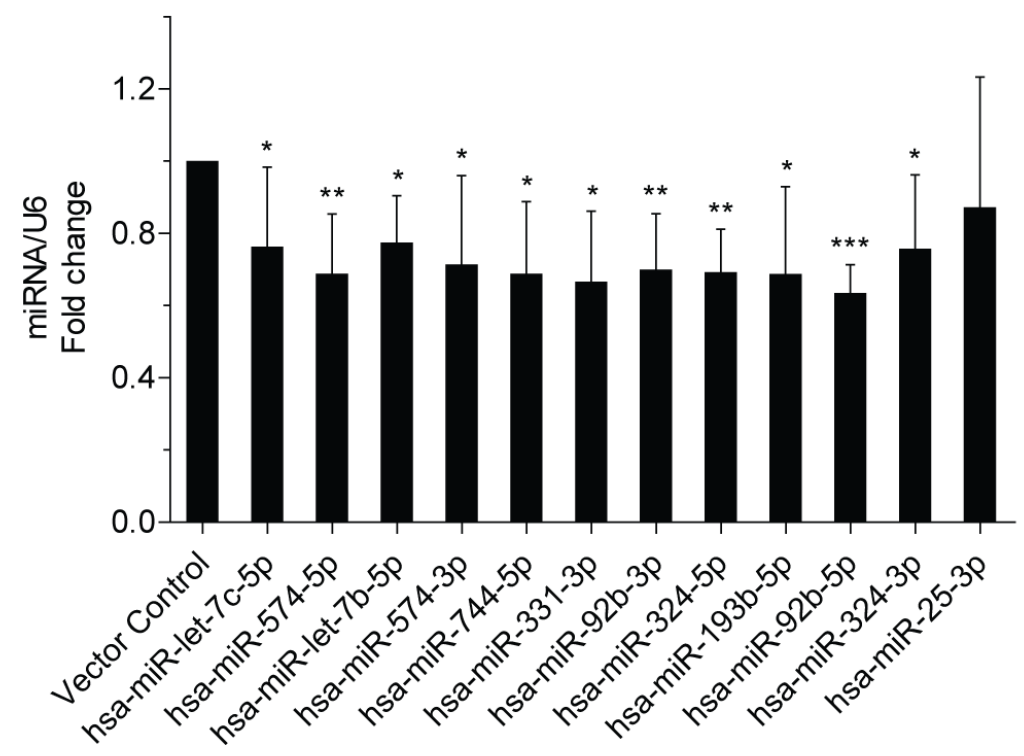

C

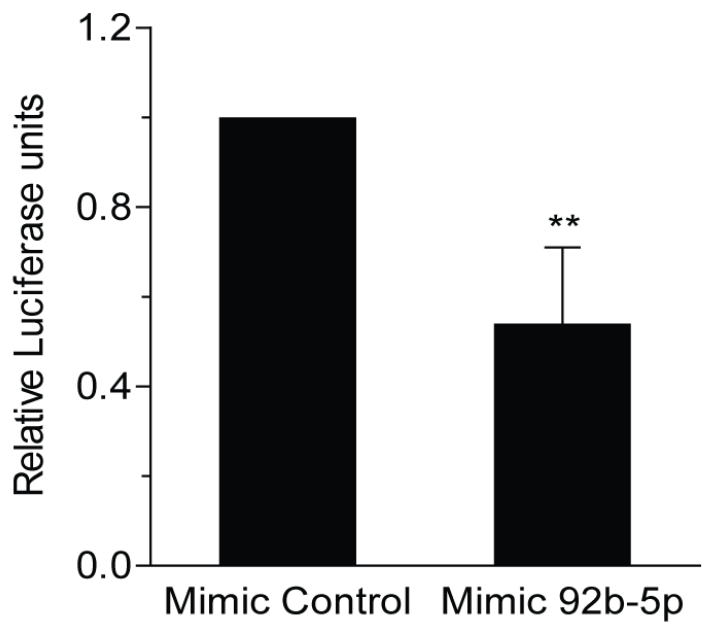

\section{Figure 7}

MiR-92b-5p is downregulated in response to HIV-1 Tat and targets 3' UTR of COR01A. Astrocytes were transfected with HIV-1 Tat expression vector for $24 \mathrm{~h}$ and were assessed for the expression of miRNAs.

(a) Heatmap was prepared using fold-change derived from absolute values of sequencing data, showing miRNAs which are downregulated by -1.3 to -2.5 -fold in the presence of HIV-1 Tat, compared to the vector control group, and predicted to target CORO1A. (b) The bar graph represents miRNA levels compared to the vector control group, analyzed using real-time PCR assay; U6 was used for normalizing the data. (c) COR01A 3' UTR was cloned downstream to the luciferase gene in the pMIR-Report vector and was cotransfected along with mimic control or mimic-92b-5p into Hela cells. Quantitative analysis shows the normalized relative luciferase activity in the indicated groups. Data shown represent four independent experiments (mean \pm S.D). ${ }^{*} p<0.05,{ }^{* *} p<0.005$, and ${ }^{* \star *} p<0.0005$. 
C

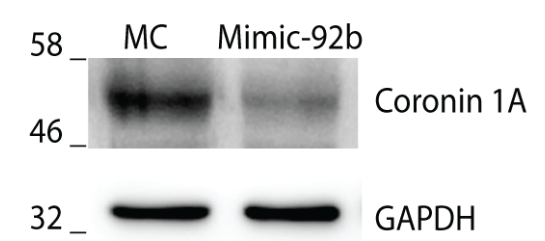

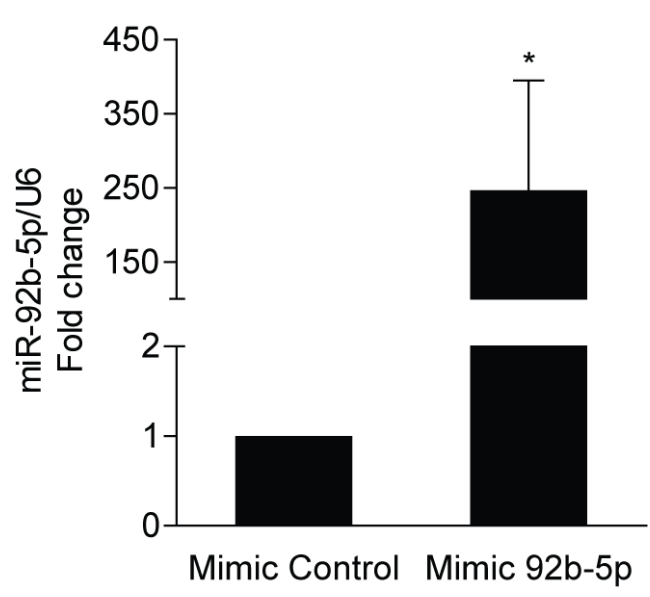

d

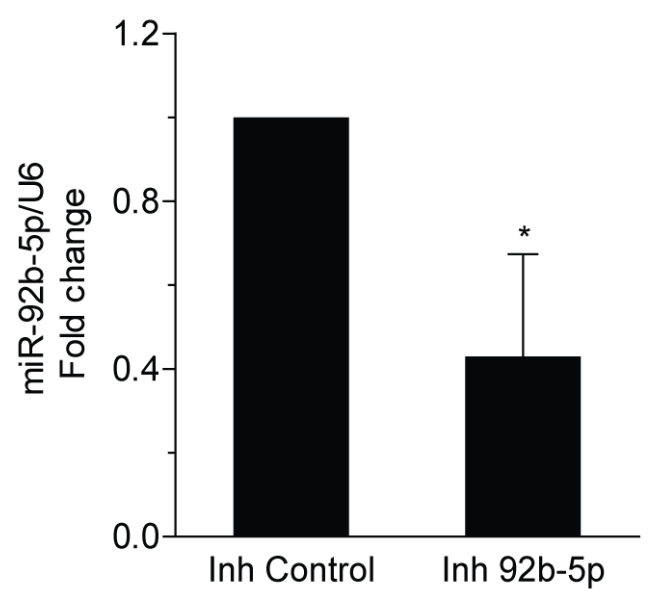

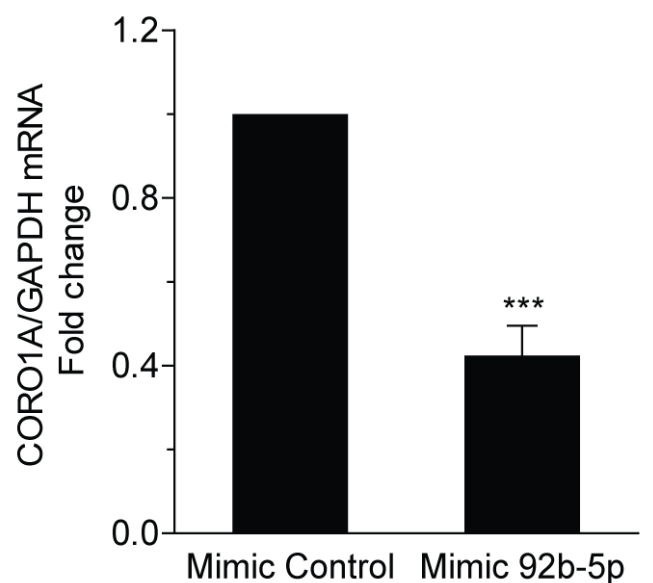

e

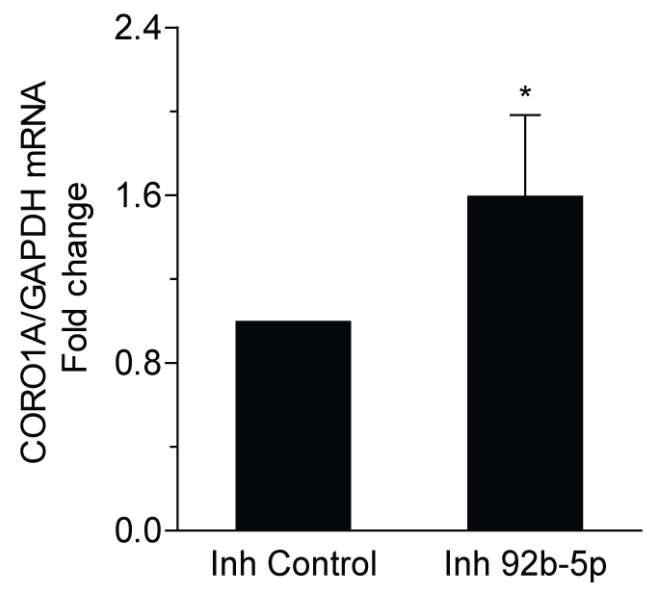

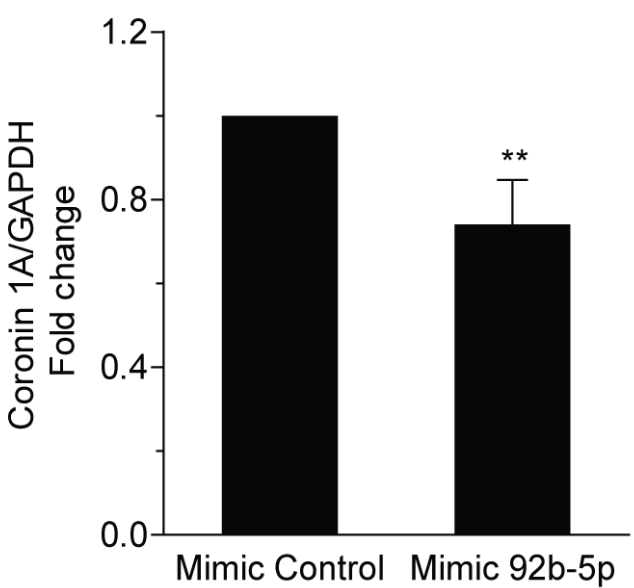

f
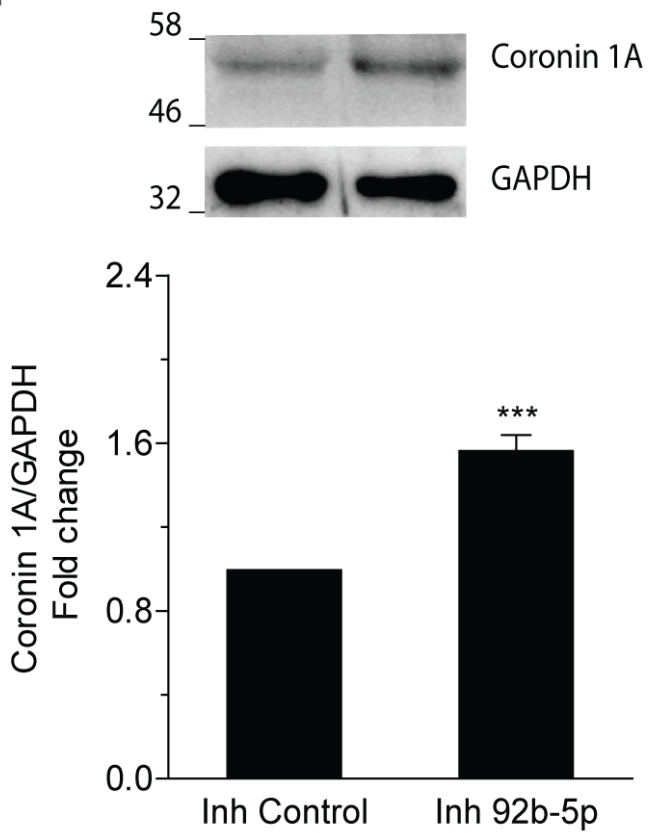

\section{Figure 8}

MiR-92b-5p mimic downregulates and inhibitor of miR-92b-5p upregulates CORO1A levels. Astrocytes were transfected with mimic-92b-5p for $48 \mathrm{~h}$. Cells were then harvested for miRNA, mRNA, and whole-cell protein. The bar graph shows the effect of mimic-92b-5p on levels of (a) miR-92b-5p, (b) CORO1A transcripts, and (c) coronin 1A protein, compared to their respective levels in the control transfected group. Similarly, astrocytes transfected with an inhibitor against miR-92b-5p were assessed for the effects on levels of (d) miR-92b-5p, (e) COR01A transcripts, and (f) coronin 1A, compared to their respective levels in the control transfected group. miRNA levels were normalized using U6 whereas mRNA and protein levels were normalized with GAPDH mRNA and protein levels, respectively. Data represents 
mean \pm S.D of at least three to four independent experiments. ${ }^{*} p<0.05,{ }^{*} p<0.005$, and ${ }^{* \star \star} p<0.0005$. Inh=inhibitor.

\section{Supplementary Files}

This is a list of supplementary files associated with this preprint. Click to download.

- AdditionalFile1.pdf 